\title{
ESTADO DE AVANCE DE LAS INVESTIGACIONES ARQUEOLÓGI- CAS EN EL SITIO EMPALME QUERANDÍES 1 (CENTRO DE LA SUBREGIÓN PAMPA HÚMEDA, PROVINCIA DE BUENOS AIRES)
}

\section{STATE OF PROGRESS OF ARCHAEOLOGICAL RESEARCHES IN EMPALME QUERANDÍES 1 SITE (CENTRE OF THE HUMID PAM- PAS SUBREGION, BUENOS AIRES PROVINCE).}

\author{
Pablo G. Messineo', María Clara Álvarez², Cristian Favier \\ Dubois $^{3}$, Pamela Steffan ${ }^{4}$ y María José Colantonio ${ }^{5}$
}

\footnotetext{
${ }^{1}$ INCUAPA-CONICET, Facultad de Ciencias Sociales (UNICEN). Avenida del Valle 5737, Olavarría (B7400JWI) E-mail: pmessine@soc.unicen.edu.ar;

${ }^{2}$ INCUAPA-CONICET, Facultad de Ciencias Sociales (UNICEN). Avenida del Valle 5737, Olavarría (B7400JWI) E-mail: malvarez@soc.unicen.edu.ar;

${ }^{3}$ INCUAPA-CONICET, Facultad de Ciencias Sociales (UNICEN). Avenida del Valle 5737, Olavarría (B7400JWI) E-mail: cfavier@coopenet.com.ar;

${ }^{4}$ INCUAPA-CONICET, Facultad de Ciencias Sociales (UNICEN). Avenida del Valle 5737, Olavarría (B7400JWI) E-mail: psteffan@soc.unicen.edu.ar

${ }^{5}$ Facultad de Ciencias Sociales (UNICEN). Avenida del Valle 5737. Olavarría (B7400JWI). E-mail: tresajose2002@yahoo.com.ar
}

Presentado el: 3/08/2012 - Aceptado el: 03/04/2013

\section{Resumen}

El objetivo de este trabajo es presentar el estado de avance de las distintas líneas de evidencia (geoambiental, cronología, tafonomía, subsistencia y tendencias tecnológicas) obtenidas a partir de las investigaciones arqueológicas llevadas a cabo en el sitio Empalme Querandies 1 (centro de la subregión Pampa Húmeda, provincia de Buenos Aires). Los estudios estratigráficos y tafonómicos sugieren que el contexto presenta una baja integridad y resolución, abarcando diferentes eventos de ocupación del Holoceno tardí inicial (entre ca. 3100-2000 años AP). El análisis faunístico evidencia que el guanaco, el venado de las pampas, el ñandú y cuatro especies de armadillos formaron parte de la dieta. Asimismo, los restos óseos de por lo menos las dos primeras especies fueron utilizados como materia prima para confeccionar instrumentos. Respecto del material lítico, las rocas mejor representadas son la ortocuarcita y la ftanita, observándose diferencias en los objetivos de producción y en las estrategias vinculadas con su utilización. En el caso de la cerámica, se registró la presencia de tiestos no decorados y decorados con motivos geométricos. Las distintas líneas de evidencia sugieren que parte de las ocupaciones de este sitio multicomponente estarían vinculadas con loci de actividades múltiples de campamentos base.

Palabras claves: Holoceno tardío inicial, Cazadores-recolectores, Geoambiente, Zooarqueología, Tecnología. 


\begin{abstract}
The aim of this article is to present the first results of an archaeological research performed at the site Empalme Querandies 1 (centre of the Humid Pampas sub-region, province of Buenos Aires). Considering a multidisciplinary approach, different types of analyses were carried out (geoenvironmental, chronology, taphonomy, subsistence, and technological trends). Stratigraphic and taphonomic studies suggest that the assemblage has a low integrity and resolution, covering different occupation events corresponding to the early Late Holocene (ca. 3100 to 2000 years BP). Faunal analyses indicate that the guanaco, the pampean deer, the greater rhea, and four armadillo species were part of the diet. Moreover, bone remains of the first two species were also used as raw material to manufacture tools. The study of the lithic assemblage shows that orthoquartzite and chert are both well represented, but there are variations in the objectives of production and in the strategies associated with their use. In the case of the pottery, undecorated as well as geometrical decorated sherds were recovered. Finally, the diverse sorts of studies indicate that part of the occupations at this multicomponent site would be related to loci of multiple activities of base camps.
\end{abstract}

Keywords: Early Late Holocene, Hunter-Gatherers, Geoenvironment, Zooarchaeology, Technology.

\title{
Introducción
}

Los primeros trabajos arqueológicos en la zona del Empalme Querandíes (centro de la subregión Pampa Húmeda, provincia de Buenos Aires) fueron efectuados por la Dra. María Teresa Boschín, a mediados de la década de 1980, momento en el que era directora del Instituto de Investigaciones Antropológicas de Olavarría (IIAO). En dicha ocasión se realizaron prospecciones y recolecciones superficiales en varios campos de la zona, aunque los resultados obtenidos durante estas investigaciones nunca fueron publicados. Otras menciones que hacen referencia al Empalme Querandíes se encuentran en los trabajos realizados por la Dra. Nora Franco a principios de la década de 1990. Estos estudios se centraron en el análisis de núcleos y raspadores hallados en contextos superficiales, con el fin de establecer tendencias tecnológicas en su aprovisionamiento y uso (Franco 1991, 1994).

En la última década, los trabajos sistemáticos en la zona del Empalme Querandíes estuvieron vinculados con el proyecto "Investigaciones arqueológicas en la cuenca superior del Arroyo Tapalqué (partidos de Olavarría y Benito Juárez, provincia de Buenos Aires)", dirigido por uno de los autores (PGM). A mediados de 2002 se efectuó la recolección superficial de materiales líticos en varios campos arados en proximidades del arroyo Tapalqué y se detectó el sitio arqueológico Empalme Querandíes 1 (en adelante, EQ1), localizado sobre la margen izquierda de dicho arroyo. En esa ocasión se recuperaron, en el perfil de la barranca y en superficie (producto de la caída de los materiales por la erosión), restos óseos de Lama guanicoe (guanaco), Ozotoceros bezoarticus (venado de las pampas) y armadillos con evidencias de explotación antrópica (huellas de corte y alteración térmica), así como diferentes materias primas líticas (Messineo 2011).

Entre noviembre de 2010 y diciembre de 2011 se realizó, a lo largo de distintas temporadas de campo, la excavación de una superficie de $6 \mathrm{~m}^{2}$ en el sitio EQ1. Durante dichos trabajos se recuperó una gran cantidad de restos de diversas especies animales, materiales líticos, fragmentos cerámicos, pigmentos minerales amarillos y rojos, fragmentos de caracoles marinos, una cuenta de valva, cáscaras de huevo e instrumentos óseos, entre otros hallazgos. Asimismo, se registraron dos concentraciones óseas de elementos de guanaco localizadas 
a diferentes profundidades, una de las cuales presentaba artefactos líticos asociados. Recientemente, se comenzó con la ampliación de otras dos cuadrículas, debido a que muchos restos de las concentraciones continuaban en la matriz sedimentaria aún no excavada. No obstante, estos datos no serán informados en esta oportunidad, ya que las tareas de campo no han sido finalizadas.

En este trabajo se presenta el estado de avance de las investigaciones llevadas a cabo en el sitio EQ1. Los objetivos del mismo son sintetizar las características geoambientales y cronológicas vinculadas con el contexto de depositación de los hallazgos, evaluar los patrones de explotación de la fauna y los aspectos tafonómicos del conjunto óseo, así como determinar las tendencias tecnomorfológicas de los materiales líticos y cerámicos. Finalmente, se pretende complementar las diferentes líneas de evidencias para discutir el grado de integridad y resolución del contexto (sensu Binford 1981), la funcionalidad del sitio y la cronología de los eventos de ocupación.

\section{Características generales de la cuenca}

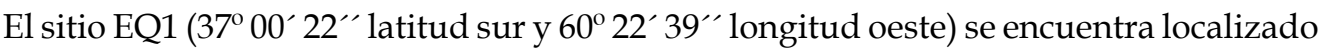
en la cuenca superior del Arroyo Tapalqué, la cual forma parte de los tributarios que drenan hacia la vertiente nororiental de Tandilia y que, a través de la cuenca del río Salado, desaguan en el Océano Atlántico (Figura 1a-b). Dentro de la cuenca se identifican dos zonas fisiográficas diferentes; una de ellas asignable a un típico paisaje de llanura generalizada que presenta un relieve poco pronunciado, el cual es surcado por el colector principal de la cuenca y por cursos tributarios de corto recorrido (Fidalgo et al. 1986). La segunda zona corresponde a las estribaciones occidentales de Tandilia, las cuales están constituidas por sierras y cerros bajos en los cuales se identifican diferentes formaciones geológicas compuestas por rocas graníticas y sedimentarias de variada naturaleza (Poiré y Spalletti 2005).

Desde el punto de vista fitogeográfico (Cabrera 1968), la cuenca superior del Arroyo Tapalqué se encuentra incluida en los distritos Pampeano Oriental y Pampeano Austral de la Provincia Pampeana (Dominio Chaqueño de la Región Neotropical). La vegetación predominante es la estepa o pseudoestepa de gramíneas, que alterna con praderas, matorrales, pajonales y juncales; mientras que en la zona serrana se encuentran estepas arbustivas e incluso bosquecillos xerófilos (Cabrera 1968; Cabrera y Willink 1980). Desde el punto de vista zoogeográfico, la mayor parte de la región pampeana se encuentra incluida en el Dominio Pampásico de la subregión Guayano-Brasileña (Ringuelet 1961). En la actualidad se registra en la cuenca la ausencia de los grandes mamíferos (i.e., venados, ciervos y guanacos) y la presencia de carnívoros y numerosos roedores, así como una gran cantidad de aves y vertebrados pisciformes (Ringuelet 1961; Cabrera y Willink 1980).

Con respecto a los diversos estudios paleoclimáticos efectuados en el centro de la subregión Pampa Húmeda, se ha reconocido durante el Holoceno tardío la alternancia de fases áridas con eventos de mayor humedad y temperatura (Fidalgo et al. 1986; Orgeira et al. 2001; Prieto et al. 2009; entre otros). Las formas típicas del paisaje, como por ejemplo, las acumulaciones de origen eólico en la llanura y los pedemontes en la proximidad de las sierras, sugieren la presencia de un clima árido-semiárido (Fidalgo et al. 1986). Asimismo, la existencia de fases subhúmedas-húmedas se evidencia a través del desarrollo de eventos pedogenéticos (Orgeira et al. 2001), por la presencia de asociaciones malacológicas y de microvertebrados registradas en varios sitios arqueológicos (Steffan 2009; Scheifler et al. 2012) 

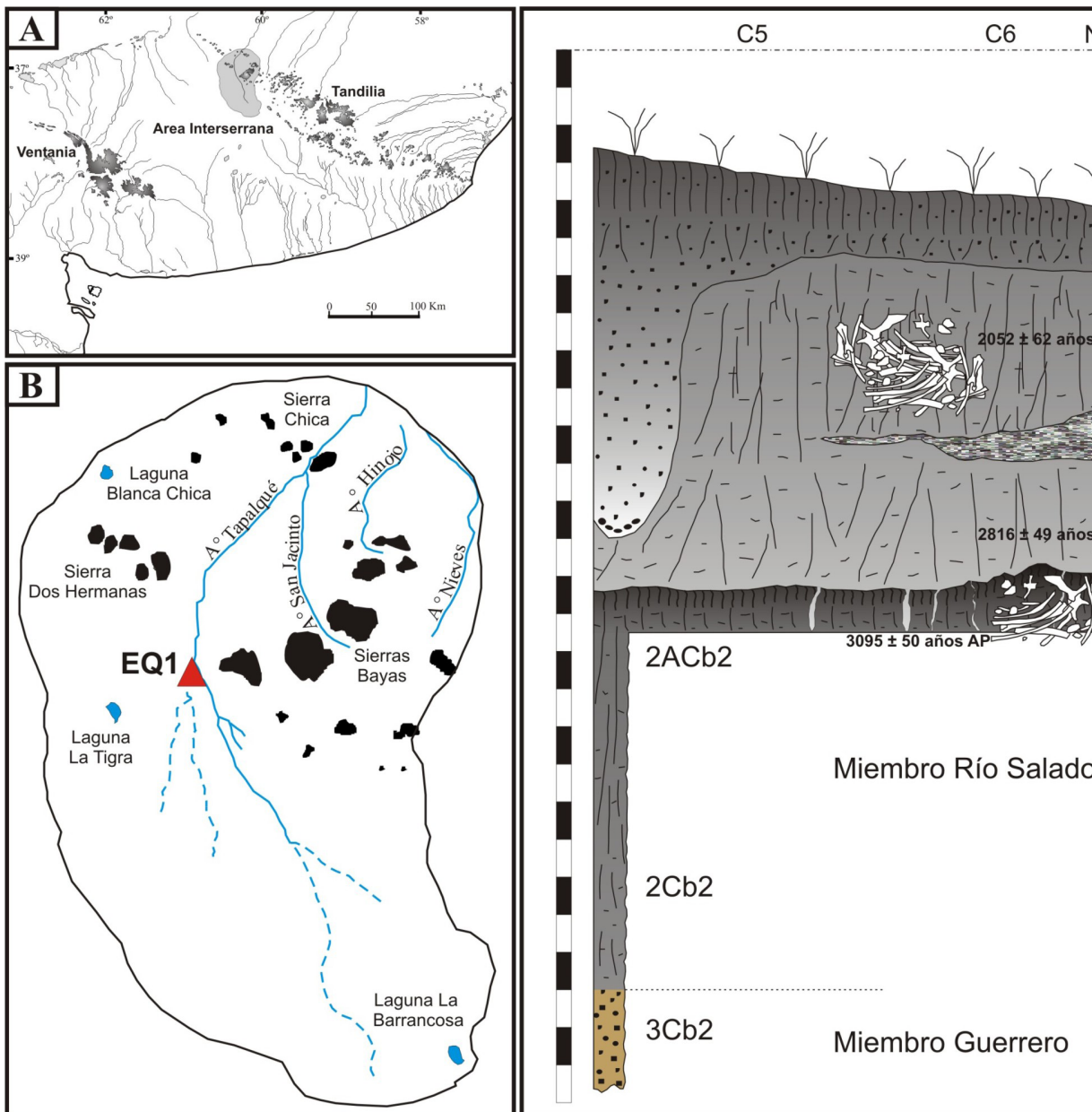

Nivel 0

Figura 1. Ubicación y perfil estratigráfico del sitio EQ1. A) Localización de la cuenca superior del Arroyo Tapalqué en el sudeste de la región pampeana; B) Emplazamiento del sitio EQ1 en la cuenca; C) Unidades geológicas y ubicación de las concentraciones óseas y dataciones radiocarbónicas.

y de estudios palinológicos (Prieto et al. 2009). A fines del Holoceno tardío, las condiciones climáticas húmedas alternaron con fases áridas, como la Pequeña Edad del Hielo (Laprida et al. 2009), hasta que se establecieron los ecosistemas modernos. Actualmente, el clima de la cuenca es subhúmedo-húmedo, mesotérmico, con nula o poca deficiencia hídrica e influenciado por el efecto moderador que ejerce el océano Atlántico (Fidalgo et al. 1991).

\section{Aspectos metodológicos}

El análisis geológico se efectuó a partir de un relevamiento de la estratigrafía a escala puntual y local (locus arqueológico y área adyacente) de acuerdo con la metodología propuesta por Butzer (1982). Para evaluar la continuidad en profundidad de las unidades expuestas en los perfiles arqueológicos se utilizó un barreno. Luego se buscó correlacionar la secuencia reconocida localmente con la geología regional. En la descripción de los perfiles se prefirió la perspectiva pedoestratigráfica por sobre la litoestratigráfica, ya que permite una calibración más adecuada de la representación temporal de las unidades en estudio y una mejor 
caracterización de los procesos postdepositacionales involucrados (Holliday et al. 1993). Con respecto a las técnicas utilizadas, se determinó la textura por medio de un contador de partículas láser, mientras que el porcentaje de materia orgánica fue realizado por el método Walkley-Black. Estos análisis fueron efectuados en el Laboratorio de Sedimentología de la Facultad de Ciencias Exactas y Naturales, Universidad Nacional de La Pampa (Santa Rosa).

En el caso del análisis del material malacológico, se tomaron 12 muestras de sedimentos a lo largo del perfil, con el objetivo de reconocer el contexto de depositación vinculado con cada una de las unidades estratigráficas. Las mismas fueron lavadas bajo agua corriente utilizando tamices de abertura de malla de $0,5 \mathrm{~mm}$. El material fue recuperado, determinado y cuantificado bajo una lupa binocular Iroscope (40X). El análisis cuantitativo efectuado consistió en el cálculo de la abundancia relativa de individuos por especie. Por su parte, el estado de preservación de las conchillas se evaluó a partir de los siguientes atributos tafonómicos: fragmentación, corrasión (Kotzian y Simões 2006), agregados (depositación química de carbonato de calcio) e incrustación interna.

Los restos faunísticos fueron determinados a distinto nivel taxonómico y anatómico. Para la totalidad de especies identificadas se obtuvieron las medidas de número de especímenes óseos identificados por taxón (NISP) y número mínimo de individuos (MNI) (Grayson 1984; Klein y Cruz-Uribe 1984; entre otros). Además, en el caso de Lama guanicoe se construyeron perfiles de partes esqueletales utilizando el número mínimo de elementos (MNE) y el número mínimo de unidades anatómicas (MAU y MAU\%) (Binford 1978; Klein y Cruz-Uribe 1984; entre otros). Para esta especie también se utilizaron medidas de intensidad y extensión de la fragmentación (NISP:MNE y Completitud\%; respectivamente) (Lyman 1994, 2008; Wolverton 2002).

Las siguientes variables tafonómicas fueron utilizadas con el objetivo de evaluar la integridad de la muestra: meteorización, marcas de roedores y carnívoros, marcas de raíces, presencia de manganeso, evidencias de pisoteo, tipo de fractura y abrasión sedimentaria (Behrensmeyer 1978; Binford 1981; Shipman 1981a; Grayson 1984; Haynes 1980; Johnson 1985; Olsen y Shipman 1988; Lyman 1994; Gutiérrez y Kaufmann 2007). Con el objetivo de identificar indicadores de procesamiento en el conjunto óseo, se consideraron las siguientes variables: alteración térmica, tipo de fractura y huellas de corte (Binford 1981; Shipman 1981b; Johnson 1985; David 1990; Benett 1999).

Se realizaron análisis tecnomorfológicos de los materiales líticos para determinar las estrategias tecnológicas involucradas y las trayectorias de producción. El conjunto fue dividido por materia prima y agrupado en categorías artefactuales amplias (sensu Aschero y Hocsman 2004), tales como desechos de talla, núcleos, artefactos formatizados y artefactos con filo y/o puntas naturales con rastros complementarios. Para el análisis de las distintas categorías se siguieron los criterios tecnomorfológicos y los atributos dimensionales planteados por diferentes investigadores (Aschero 1975, 1983; Bellelli et al. 1985-1987; Aschero y Hocsman 2004; entre otros). Sin embargo, y dada la extensión del trabajo, en la presentación de los resultados sólo algunas de las variables serán descriptas: tipo de materia prima, tamaños y módulos, grupos tipológicos y formas base en artefactos formatizados, tipos de núcleo y dirección de los lascados, tipos de lasca y talón, entre otras.

Los análisis de los fragmentos cerámicos en esta primera instancia fueron realizados con un nivel de detalle general. Para el estudio de los atributos tecnomorfológicos se siguieron 
las propuestas desarrolladas por diferentes investigadores (Rice 1987; Orton et al. 1997; entre otros), aunque sólo se tomaron en consideración algunas variables, como por ejemplo, la frecuencia de piezas, partes de la vasija, técnica de fabricación, así como presencia y tipo de decoración. Otras variables (e.g., tipos de borde, tratamiento de las superficies, textura de la pasta, tipos y distribución de las inclusiones, cocción de la pasta y alteraciones postdepositacionales) serán consideradas en futuros análisis.

\section{Sitio Empalme Querandíes 1}

\section{Estudios geoambientales y cronología}

El perfil estratigráfico relevado en el sitio EQ1 corresponde a la pared oeste que quedó expuesta como producto de la excavación de las cuadrículas 5 y 6 . Además, a partir de los $155 \mathrm{~cm}$ de profundidad desde el nivel 0 , las muestras de sedimento fueron obtenidas por medio de un barreno, hasta llegar a una profundidad de $275 \mathrm{~cm}$ (Figura 1c). A continuación se describen, de arriba hacia abajo, las distintas unidades estratigráficas reconocidas.

Entre los 25 y $50 \mathrm{~cm}$ desde el nivel 0 el sedimento es franco-limoso, color castaño oscuro, con una estructura migajosa y abundantes radículas. El porcentaje de materia orgánica es de $3,51 \%$ y su límite inferior es claro y suave. Esta unidad corresponde al horizonte A del suelo actual. Entre los 50 y 55/130 cm el sedimento es limoso, color castaño claro, masivo y con abundantes radículas. Hacia la sección izquierda del perfil su límite inferior es abrupto y de geometría cóncava, presentando alineación de material bioclástico hacia la base (principalmente fragmentos de conchilla). El porcentaje de materia orgánica es de 1,61\%. Esta unidad corresponde al horizonte $C$ del suelo actual y apoya en discordancia erosiva sobre la unidad infrayacente (Figura 1c). Estas discordancias parecen vincularse con la acción conjunta de eventos de inundación y la acción de animales de hábitos fosoriales (posiblemente armadillos), los cuales han generado perturbaciones de importancia en la estratigrafía del sitio.

Entre los 55 y $110 \mathrm{~cm}$ de la sección derecha del perfil el sedimento es limoso y de color castaño oscuro, tiene una estructura en bloques angulosos medianos y débiles, así como algunas radículas en la parte superior, su límite inferior es claro y suave. El mismo presenta un porcentaje de materia orgánica de 2,49\%. Esta unidad corresponde al horizonte A del suelo enterrado 2Ab1, que al parecer es de tipo cumúlico. En la base de este horizonte de suelo se registra, sólo en la cuadrícula 6, un rasgo lenticular constituido por una acumulación de moluscos. Entre los 110 y $145 \mathrm{~cm}$ el sedimento es limoso, de color castaño claro, con una estructura en bloques angulosos medianos y débiles, su límite inferior es abrupto y suave. El porcentaje de materia orgánica es de $0,67 \%$ y corresponde al horizonte $C$ del suelo enterrado 2Ab1 (Figura 1c).

Entre los 145 y $155 \mathrm{~cm}$ el sedimento es limoso, de color castaño y masivo, su límite inferior es claro y suave. El porcentaje de materia orgánica es de $0,80 \%$ y corresponde al horizonte A del suelo enterrado 2Ab2. Entre los 155 y $215 \mathrm{~cm}$ el sedimento es limoso, masivo, de un color castaño algo más claro que en la unidad anterior y su límite inferior es claro a gradual. Corresponde al horizonte AC del suelo enterrado 2Ab2. Entre los 215 y los $250 \mathrm{~cm}$ el sedimento es limoso, de color castaño claro y masivo, con límite inferior claro. Se trata del horizonte C del suelo enterrado 2Ab2. Por debajo de los $250 \mathrm{~cm}$ el sedimento es arenoso, de color castaño verdoso y aspecto masivo. Este constituye el horizonte $\mathrm{C}$ del suelo enterrado $3 \mathrm{Cb} 2$, asignable al Miembro Guerrero de la formación Luján, de edad Pleistoceno tardío (Figura 1c). 
Para llevar a cabo el análisis del material malacológico se muestreó el perfil oeste de la cuadrícula 6 del sitio, ya que en el mismo se registró el rasgo lenticular con la acumulación de abundantes moluscos. Los resultados que aquí se presentan informan acerca de los niveles medios e inferiores de excavación (entre los 70 y $150 \mathrm{~cm}$ desde el nivel 0). La malacofauna recuperada $(n=3975)$ está representada por siete especies de gastrópodos continentales, siendo cuatro de ellas acuáticas (Heleobia parchappii, Biomphalaria peregrina, Antillorbis nordestensis y Uncancylus concentricus), una palustre (Succinea meridionalis) y dos terrestres (Miradiscops brasiliensis y Zilchogyra costellata).

La frecuencia y asociación de especies permiten inferir características ambientales relevantes para las distintas unidades estratigráficas reconocidas. En el horizonte A del suelo enterrado $2 \mathrm{Ab} 1$ (entre 70 y $95 \mathrm{~cm}$ ) se destaca la abundancia de la especie palustre, coincidente con condiciones vinculadas con la formación de suelos cumúlicos. Por debajo, en el rasgo lenticular asociado con la base del horizonte A del suelo enterrado 2Ab1 (entre 95 y $108 \mathrm{~cm}$ ), se registra una marcada predominancia de especies acuáticas características de ambientes lacustres (Tabla 1). Asimismo, es notable la abundancia de Succinea meridionalis y la asociación de dichos moluscos con restos de peces y plantas acuáticas. El análisis tafonómico de las conchillas dentro del rasgo indica que el grado de fragmentación para todas las especies es bajo ( 20\%). Por su parte, Antillorbis nordestensis presentó abundante corrasión ( $70 \%)$, la cual fue menor en Biomphalaria peregrina $(46 \%)$, mientras que el resto de los taxones mostraron valores menores al 10\%. En general, las especies acuáticas presentaron la mayor fragmentación, corrasión e incrustación interna. Estos datos permiten inferir que la asociación de los restos en el rasgo se pudo generar por el ingreso de un flujo de sedimento asociado con una inundación como producto del desborde de un curso cercano.

\begin{tabular}{|c|c|c|c|c|c|c|c|c|c|}
\hline \multirow[b]{2}{*}{$\begin{array}{l}\text { Profundidad } \\
\text { en cm desde } \\
\text { el nivel } 0\end{array}$} & \multirow[b]{2}{*}{ Unidad } & \multicolumn{7}{|c|}{ Gastrópodos } & \multirow[b]{2}{*}{$\begin{array}{c}\text { Total } \\
\text { por } \\
\text { muestreo }\end{array}$} \\
\hline & & 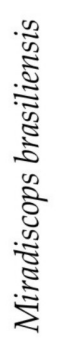 & 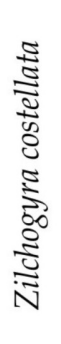 & 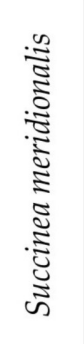 & 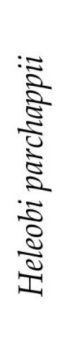 & 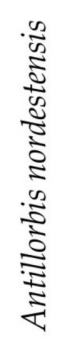 & 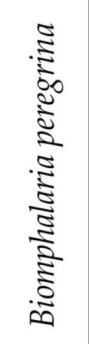 & 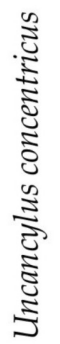 & \\
\hline $70-80$ & $2 \mathrm{Ab} 1$ & 0 & 0 & 25 & 0 & 0 & 1 & 0 & 26 \\
\hline $80-87$ & 2Ab1 & 10 & 0 & 41 & 5 & 18 & 36 & 1 & 111 \\
\hline $87-95$ & $2 \mathrm{Ab} 1$ & 21 & 1 & 420 & 89 & 0 & 489 & 8 & 1028 \\
\hline $95-108$ & Rasgo (2Ab1) & 25 & 1 & 744 & 189 & 242 & 1351 & 15 & 2567 \\
\hline $108-115$ & $2 \mathrm{Cb} 1$ & 9 & 0 & 100 & 2 & 0 & 40 & 0 & 151 \\
\hline $115-125$ & $2 \mathrm{Cb} 1$ & 3 & 0 & 30 & 0 & 0 & 5 & 0 & 38 \\
\hline $125-140$ & $2 \mathrm{Cb} 1$ & 5 & 0 & 4 & 0 & 0 & 1 & 0 & 10 \\
\hline $140-150$ & $2 \mathrm{Ab} 2$ & 12 & 0 & 17 & 1 & 0 & 14 & 0 & 44 \\
\hline \multicolumn{2}{|c|}{ Total por especie } & 85 & 2 & 1381 & 286 & 260 & 1937 & 24 & 3975 \\
\hline
\end{tabular}

Tabla 1. Representación de las especies de gastrópodos identificadas en el muestreo de EQ1. 
En el horizonte $\mathrm{C}$ del suelo enterrado 2Ab1, se observan leves variaciones dentro del mismo depósito. Entre 108 y $115 \mathrm{~cm}$ se infieren condiciones palustres, al mismo tiempo que se observa un incremento de especies fluviales/lacustres con anterioridad al evento de inundación. En la parte media (entre 115 y $125 \mathrm{~cm}$ ) se reconocen características palustres, mientras que hacia la base se registra la presencia de un horizonte de suelo vegetado (entre 125 y $140 \mathrm{~cm}$ ). Por último, en el horizonte A del suelo enterrado $2 \mathrm{Ab} 2$, se encuentra mayoritariamente representada la especie Succinea meridionalis, que habita sectores pantanosos.

Con relación a la cronología, se han datado tres muestras correspondientes a huesos de Lama guanicoe, los cuales procedían de tres niveles diferentes de excavación, todos ellos de la cuadrícula 6 (Tabla 2). En primer lugar, un metatarso con huellas de corte asociado con el suelo enterrado $2 \mathrm{Ab} 2$ arrojó una edad de $3095 \pm 50$ años AP (AA-94559). Por otro lado, una tibia utilizada como soporte de un instrumento óseo que se localizaba en la unidad estratigráfica 2Cb1 dio una edad de $2816 \pm 49$ años AP (AA-94558). Por último, en el horizonte A del suelo enterrado $2 \mathrm{Ab} 1$ se recuperó un radiocúbito con una fractura antrópica y dos lascas óseas que remontaban con la diáfisis. Un fragmento de este espécimen proporcionó una edad de $2052 \pm 62$ años AP (AA-94557).

A partir de los resultados de los fechados radiocarbónicos podría proponerse que en el sitio EQ1 han existido al menos tres eventos de ocupación. Sin embargo, los materiales arqueológicos se distribuyen homogéneamente a lo largo de toda la secuencia, desde el suelo actual hasta la parte superior del horizonte AC del suelo enterrado $2 \mathrm{Ab} 2$, por lo cual no fue posible separar componentes o grupos de niveles que permitan correlacionarlos con las dataciones obtenidas. Además, en el perfil estratigráfico se observa la presencia de cuevas rellenadas, que indican la acción de animales de hábitos fosoriales. Por último, durante la excavación de las unidades $2 \mathrm{Cb} 1$ y $2 \mathrm{Ab} 2$ se registraron grietas en el sedimento, las cuales contenían materiales en posición vertical que probablemente hayan migrado, quedando atrapadas en ellas. Por todo lo expresado, el conjunto arqueológico fue analizado como una unidad, en la cual se promediaron distintos eventos de ocupación correspondientes al Holoceno tardío inicial (entre ca. 3100 y 2000 años AP).

\begin{tabular}{|c|c|c|c|c|c|c|c|}
\hline $\mathbf{N}^{0}$ Lab. & $\mathrm{N}^{\mathrm{o}}$ Inventario & Elemento & UE & Edad ${ }^{14} \mathrm{C}$ & ${ }^{13} \mathrm{C}$ & $\begin{array}{c}\text { Edad cal. AP } \\
\text { (1 sigma)* }\end{array}$ & $\begin{array}{l}\text { Edad cal. AP } \\
\text { (2 sigmas)* }\end{array}$ \\
\hline AA-94557 & FCS.EQ1.1172 & Radiocúbito & $2 \mathrm{Ab} 1$ & $2052 \pm 62$ & -23.9 & $1873-2006$ & $1818-2126$ \\
\hline AA- 94558 & FCS.EQ1.1382 & Tibia & $2 \mathrm{Cb} 1$ & $2816 \pm 49$ & -19.9 & $2784-2888$ & $2756-2973$ \\
\hline AA-94559 & FCS.EQ1.1464 & Metatarso & $2 \mathrm{Ab} 2$ & $3095 \pm 50$ & -18.6 & $3206-3341$ & $3078-3368$ \\
\hline
\end{tabular}

En el horizonte $\mathrm{C}$ del suelo enterrado $2 \mathrm{Ab1}$, se observan leves variaciones dentro del mismo depósito. Entre 108 y $115 \mathrm{~cm}$ se infieren condiciones palustres, al mismo tiempo que se observa un incremento de especies fluviales/lacustres con anterioridad al evento de inundación. En la parte media (entre 115 y $125 \mathrm{~cm}$ ) se reconocen características palustres, mientras que hacia la base se registra la presencia de un horizonte de suelo vegetado (entre 125 y $140 \mathrm{~cm}$ ). Por último, en el horizonte A del suelo enterrado $2 \mathrm{Ab} 2$, se encuentra mayoritariamente representada la especie Succinea meridionalis, que habita sectores pantanosos.

Con relación a la cronología, se han datado tres muestras correspondientes a huesos de Lama guanicoe, los cuales procedían de tres niveles diferentes de excavación, todos ellos de la cuadrícula 6 (Tabla 2). En primer lugar, un metatarso con huellas de corte asociado con el 
suelo enterrado 2Ab2 arrojó una edad de $3095 \pm 50$ años AP (AA-94559). Por otro lado, una tibia utilizada como soporte de un instrumento óseo que se localizaba en la unidad estratigráfica 2Cb1 dio una edad de $2816 \pm 49$ años AP (AA-94558). Por último, en el horizonte A del suelo enterrado $2 \mathrm{Ab} 1$ se recuperó un radiocúbito con una fractura antrópica y dos lascas óseas que remontaban con la diáfisis. Un fragmento de este espécimen proporcionó una edad de $2052 \pm 62$ años AP (AA-94557).

A partir de los resultados de los fechados radiocarbónicos podría proponerse que en el sitio EQ1 han existido al menos tres eventos de ocupación. Sin embargo, los materiales arqueológicos se distribuyen homogéneamente a lo largo de toda la secuencia, desde el suelo actual hasta la parte superior del horizonte AC del suelo enterrado 2Ab2, por lo cual no fue posible separar componentes o grupos de niveles que permitan correlacionarlos con las dataciones obtenidas. Además, en el perfil estratigráfico se observa la presencia de cuevas rellenadas, que indican la acción de animales de hábitos fosoriales. Por último, durante la excavación de las unidades $2 \mathrm{Cb} 1$ y $2 \mathrm{Ab} 2$ se registraron grietas en el sedimento, las cuales contenían materiales en posición vertical que probablemente hayan migrado, quedando atrapadas en ellas. Por todo lo expresado, el conjunto arqueológico fue analizado como una unidad, en la cual se promediaron distintos eventos de ocupación correspondientes al Holoceno tardío inicial (entre ca. 3100 y 2000 años AP).

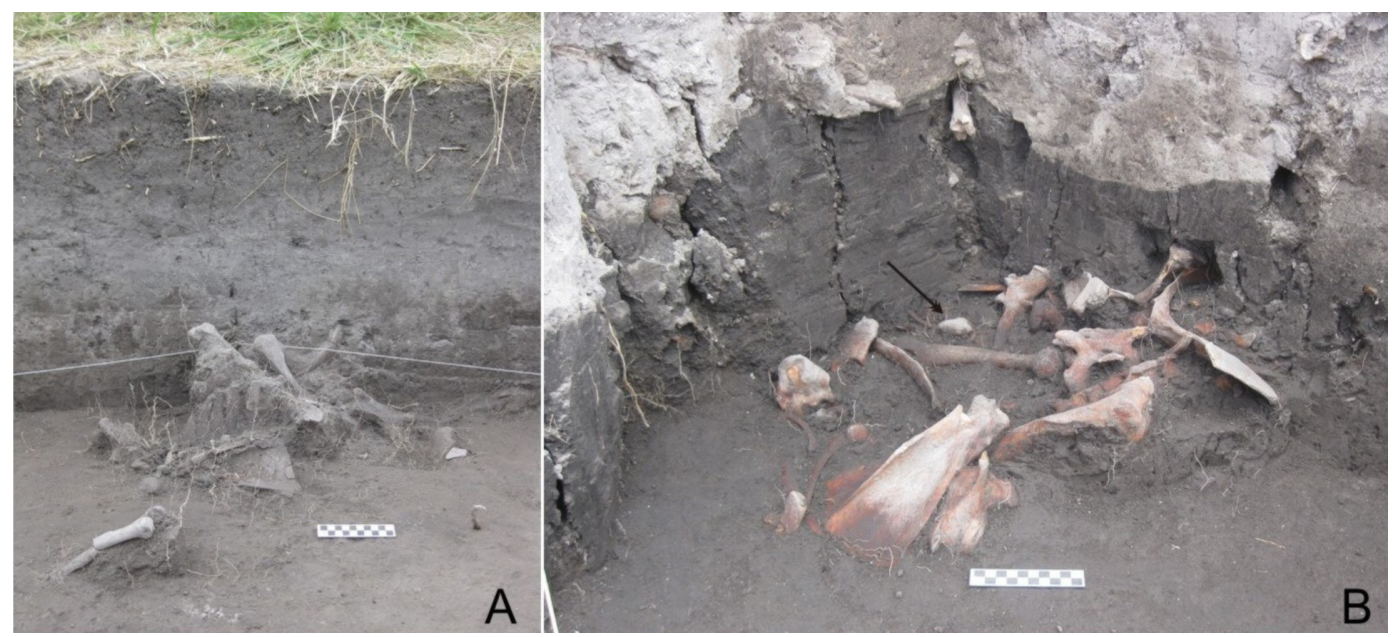

Figura 2. Vista de las concentraciones registradas en EQ1. A) Concentración 1 en la unidad estratigráfica 2Ab1; B) Concentración 2 en la unidad estratigráfica 2Ab2. La flecha señala un artefacto lítico.

\section{Análisis de los restos faunísticos}

La muestra analizada para el sitio EQ1 consistió en todos los restos faunísticos provenientes de las cuadrículas 1 y 6, con excepción de los microvertebrados, que serán estudiados por el Lic. Nahuel Scheifler. Esto hace un total de 77.913 especímenes, gran parte de los cuales son fragmentos indeterminados (ca. 93\%). Un aspecto destacable del conjunto es la presencia de dos concentraciones óseas asignables a dos eventos diferentes. La concentración 1, localizada en la unidad estratigráfica 2Ab1 (entre los 70 y $95 \mathrm{~cm}$ ), se vincula con el fechado de 2052 años AP obtenido sobre el radiocúbito. La concentración 2, registrada en la unidad estratigráfica 2Ab2 (entre los 135 y $155 \mathrm{~cm}$ ), se corresponde con el fechado de 3095 años AP obtenido sobre el metatarso (Figura 1c). A continuación se presentan por separado los resultados obtenidos de las concentraciones óseas y del resto de los materiales faunísticos recuperados en las dos cuadrículas analizadas. 
Ambas concentraciones estaban compuestas casi en su totalidad por huesos completos de Lama guanicoe que se encontraban en su mayoría articulados entre sí (Figura 2). En la concentración 1 se registraron 110 especímenes, de los cuales ca. 95\% correspondía a Lama guanicoe, ca. $2 \%$ a Artiodactyla, ca. $2 \%$ a mesomamíferos y ca. $1 \%$ a Dasypodidae. Para Lama guanicoe se determino un NISP de 105 y un MNE de 71. Los grupos de edad de esta especie fueron estimados sobre la base de la fusión ósea (Kaufmann 2009) y corresponden a un individuo neonato, uno juvenil y dos adultos, lo que totalizó un MNI de cuatro. En la concentración 2 se determinaron 64 especímenes, de los cuales ca. 91\% fue asignado a Lama guanicoe, ca. 1,5\% a Lagostomus maximus (vizcacha), ca. $6 \%$ a Dasypodidae y ca. 1,5\% a Artiodactyla. Para Lama guanicoe se registraron 59 especímenes y se estimó un MNE de 52. Los grupos de edad estaban

\begin{tabular}{|c|c|c|c|c|}
\hline Taxón & NISP & NISP\% $\%$ & MNI & $\mathbf{P}$ \\
\hline Mamífero grande (post-hispánico) & 2 & 0,18 & NA & - \\
\hline Ovis aries & 8 & 0,72 & 2 & - \\
\hline Equus caballus & 2 & 0,18 & 1 & - \\
\hline Artiodactyla & 134 & 12,13 & NA & - \\
\hline Lama guanicoe & 629 & 56,92 & 9 & $\mathrm{P}$ \\
\hline Ozotoceros bezoarticus & 84 & 7,60 & 3 & $\mathrm{P}$ \\
\hline Carnivora & 4 & 0,36 & NA & - \\
\hline Canidae & 16 & 1,45 & 1 & - \\
\hline Conepatus sp. & 3 & 0,27 & 1 & - \\
\hline Mesomamífero & 92 & 8,33 & NA & - \\
\hline Myocastor coypus & 1 & 0,09 & 1 & $\mathrm{P}$ \\
\hline Dolichotis patagomun & 2 & 0,18 & 1 & - \\
\hline Lagostomus maximus & 63 & 5,70 & 2 & $\mathrm{P}$ \\
\hline Dasypodidae & 31 & 2,81 & NA & - \\
\hline Chaetophractus villosus & 16 & 1,45 & 2 & $\mathrm{P}$ \\
\hline Ave & 4 & 0,36 & NA & - \\
\hline Tinamidae & 5 & 0,45 & 1 & - \\
\hline Rhea americana & 7 & 0,63 & 1 & $\mathrm{P}$ \\
\hline Osteichtyes & 2 & 0,18 & NA & - \\
\hline Subtotal taxón & 1105 & 100 & - & - \\
\hline Gastrópodo marino & 4 & - & NA & - \\
\hline Bivalvo marino & 1 & - & 1 & - \\
\hline Rhea americana (cáscara de huevo) & 654 & - & NA & - \\
\hline Dasypodidae (placas) & 1471 & - & NA & - \\
\hline Chaetophractus villosus (placas) & 986 & - & 2 & $\mathrm{P}$ \\
\hline Zaedyus pichiy (placas) & 524 & - & 2 & $\mathrm{P}$ \\
\hline Dasypus hybridus (placas) & 187 & - & 1 & $\mathrm{P}$ \\
\hline Tolypeutes matacus (placas) & 40 & - & 1 & $\mathrm{P}$ \\
\hline Total taxón & 4972 & - & - & - \\
\hline Fragmentos indeterminados $<4 \mathrm{~cm}$ & 72.767 & - & - & - \\
\hline Total & 77.739 & - & - & - \\
\hline
\end{tabular}

Tabla 3. Representación taxonómica de la muestra del sitio EQ1 (no se encuentran incluidas las concentraciones). $\mathrm{P}=$ Evidencia de procesamiento. $\mathrm{NA}=$ No aplica. 
representados por un individuo neonato y dos adultos, lo que suma un MNI de tres (Álvarez 2012). En ninguna de las dos concentraciones se registraron especímenes con fracturas antrópicas o alteración térmica. En la concentración 1 se reconocieron cinco especímenes con huellas de corte $(4,5 \%)$, mientras que para la concentración 2 se identificaron sólo dos (3,1\%).

En el resto de la muestra (sin considerar las concentraciones), el número total de especímenes fue de 77.739. Dentro de este conjunto, el 93,6\% de los especímenes corresponde a fragmentos indeterminados menores a $4 \mathrm{~cm}$ (Tabla 3). Entre los taxones determinados se contabilizó un total de 3208 especímenes correspondientes a placas óseas de armadillos, estando representada principalmente la familia Dasypodidae (ca. 46\%) y las especies Chaetophractus villosus (peludo, ca. 31\%), Zaedyus pichiy (piche, ca. 16\%), Dasypus hybridus (mulita, ca. 6\%) y Tolypeutes matacus (quirquincho bola, ca. 1\%). Se recuperaron cuatro especímenes de gastrópodos marinos y uno de un bivalvo, los cuales no pudieron ser asignados a niveles taxonómicos más específicos (por fuera de la muestra analizada se halló una cuenta confeccionada sobre una valva de molusco indeterminada). También fueron identificados 654 especímenes correspondientes a cáscara de huevo de Rheidae, aunque probablemente correspondan a la especie Rhea americana (ñandú) (Álvarez 2012).

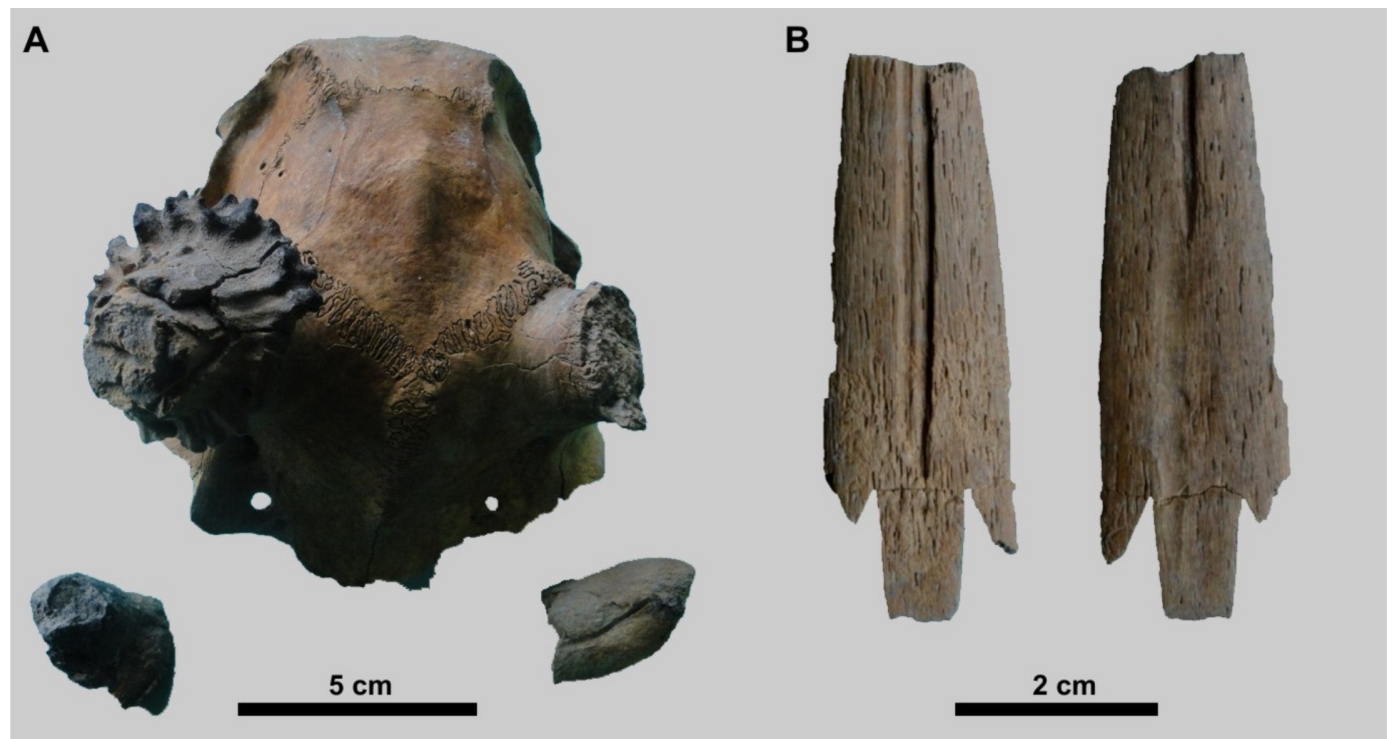

Figura 3. Procesamiento antrópico y tecnología ósea. A) Cráneo de Ozotoceros bezoarticus con las rosetas y astas quemadas; B) Punta de proyectil en hueso.

Con excepción de los casos mencionados, considerando la cantidad de especímenes, la especie mejor representada es Lama guanicoe (MNE=277 y MNI=9), la cual es seguida en frecuencia por los mesomamíferos indeterminados y Ozotoceros bezoarticus (Tabla 3). Se recuperó también una cantidad significativa de restos de Lagostomus maximus y una baja frecuencia de Chaetophracuts villosus y Canidae. Entre las aves están presentes la especie Rhea americana y la familia Tinamidae (tinamúes). En muy bajas frecuencias se registraron especímenes de Conepatus sp. (zorrino), Dolichotis patagonum (mara), Osteichtyes y Myocastor coypus (coipo). Finalmente, se identificaron restos de las especies europeas Equus caballus (caballo) y Ovis aries (oveja). Estas son claramente intrusivas y se encontraban asociadas con la presencia de cuevas (Álvarez 2012). 
De los 46 especímenes dentarios asignados a Lama guanicoe, muy pocos se encontraban completos y la mayoría correspondían a fragmentos de corona de molares indeterminados. De estos, sólo pudieron determinarse los grupos etarios para ocho especímenes: tres tenían entre 0 y 15 días de edad, dos entre 15 días y 6 meses de edad, uno entre 9 y 12 meses de edad, uno entre 3 y 4 años de edad y uno más de cuatro años de edad (Álvarez 2012). Considerando estas categorías y las fechas conocidas de parición de Lama guanicoe (Kaufmann 2009), puede proponerse que el sitio habría sido ocupado durante distintos momentos del año.

Los taxones que presentaron evidencias de procesamiento antrópico fueron Lama guanicoe, Ozotoceros bezoarticus, Myocastor coypus, Lagostomus maximus, Rhea americana y las cuatro especies de armadillo (Tabla 3). Del total del conjunto, ca. $6 \%$ de los especímenes presentaba huellas de corte, $c a .7 \%$ fracturas antrópicas y ca. $1 \%$ alteración térmica. Para Lama guanicoe y Ozotoceros bezoarticus se identificó una mayor frecuencia de huellas de fileteo (50\% y 33,34\%, respectivamente), seguidas por las de desarticulación ( $21,05 \%$ y $22,2 \%)$, cuereo ( $10,53 \%$ y $22,2 \%)$

\begin{tabular}{|c|c|c|c|}
\hline Variable & $\begin{array}{c}\text { NISP } \% \\
\text { Concentración 1 }\end{array}$ & $\begin{array}{c}\text { NISP\% } \% \\
\text { Concentración } 2\end{array}$ & NISP $\%$ Total \\
\hline \multicolumn{4}{|l|}{ Meteorización } \\
\hline Estadío 0 & 93,40 & 86,45 & 87,43 \\
\hline Estadío 1 & 6,60 & 11,86 & 8,56 \\
\hline Estadío 2 & - & 1,69 & 3,68 \\
\hline Estadío 3 & - & - & 0,33 \\
\hline Estadío 4 & - & - & - \\
\hline Estadío 5 & - & - & - \\
\hline \multicolumn{4}{|l|}{ Abrasión } \\
\hline Estadío 0 & 1,91 & 8,48 & 23,94 \\
\hline Estadío 1 & 97,14 & 91,52 & 69,88 \\
\hline Estadío 2 & 0,95 & - & 5,96 \\
\hline Estadío 2/3 & - & - & 0,11 \\
\hline Estadío 3 & - & - & 0,11 \\
\hline Manganeso & 0,95 & 1,69 & 0,54 \\
\hline Acción de raíces & 77,14 & 35,59 & 30,23 \\
\hline Marcas de carnívoros & - & - & 0,65 \\
\hline Marcas de roedores & - & - & 1,84 \\
\hline Marcas de pisoteo & - & 1,69 & 2,17 \\
\hline Fracturas & 68,2 & 25,10 & 62,84 \\
\hline Irregulares & 24,90 & 40 & 71,54 \\
\hline Actuales & 75,10 & 60 & 21,46 \\
\hline Helicoidales & - & - & 7 \\
\hline
\end{tabular}

Tabla 4. Variables tafonómicas para los taxones de porte mediano y grande (expresadas como NISP\%) recuperados en las dos concentraciones y en el conjunto total (no se consideraron los restos indeterminables, dientes, placas óseas, cáscaras de huevo y restos óseos de microvertebrados). 
y aquellas que no pudieron ser asignadas a una actividad específica. También se destaca la presencia de un cráneo de Ozotoceros bezoarticus articulado con cuatro vértebras cervicales. Este espécimen presentó alteración térmica en la base y en el cuerpo de las rosetas. Asociado al cráneo se hallaron fragmentos de asta quemados que remontaban con las mismas (Figura 3a).

En la muestra analizada se reconocieron dos instrumentos óseos. Uno de ellos fue manufacturado sobre la diáfisis lateral de una tibia de Lama guanicoe, la cual conserva la epífisis proximal. La otra pieza corresponde a un fragmento distal de un instrumento confeccionado sobre un hueso indeterminado, posiblemente correspondiente a Rhea americana (Álvarez 2012). Finalmente, en la cuadrícula 2 (no incluida en la muestra analizada) se recuperó una punta de proyectil manufacturada en hueso. La misma posee el ápice fracturado y presenta acanaladura sobre ambas caras, su base es pedunculada, con aletas y toda su superficie se encuentra pulida (Figura 3b). Dada la elevada formatización de este instrumento, no pudo determinarse sobre qué elemento esqueletario y especie fue confeccionado (Messineo et al. 2011; Álvarez 2012).

Con relación a los aspectos tafonómicos, los restos faunísticos del conjunto se caracterizan por la presencia de abrasión sedimentaria (ca. $78 \%$ ), aunque la mayoría de ellos ( $c a$. $70 \%$ ) se encuentra en el estadío 1 y en escasa proporción en los estadíos 2, 2/3 y 3 (Gutiérrez y Kaufmann 2007). Por su parte, en ambas concentraciones, la abrasión sedimentaria se observa en más del 90\% de los especímenes de Lama guanicoe, mayoritariamente en el estadío 1 (Tabla 4). El perfil de meteorización mostró una baja incidencia de este agente en el conjunto general (ca. 12\% en los estadíos más bajos) y en ambas concentraciones $(6,6 \%$ y $13,55 \%$ ), en tanto que el resto de los especímenes se encuentra en el estadío 0 . El resto de las variables no tuvo incidencia o la misma fue muy baja. La única excepción la constituye la acción de raíces, agente que afectó considerablemente la superficie cortical de los huesos, principalmente de la concentración 1 (ca. $77 \%)$, la cual está vinculada con el horizonte A del suelo enterrado 2Ab1 (Figura 2a). Con relación a la alta fragmentación que presenta el conjunto, la misma podría estar vinculada con procesos naturales, tales como la acción de raíces y en menor medida el pisoteo. Los análisis de la intensidad y extensión de la fragmentación indicaron que si bien las fracturas de los huesos largos podrían estar asociadas con la extracción de médula, los elementos axiales no habrían sido procesados con el fin de adquirir la grasa ósea, dado que los mismos presentan bajas tasas de NISP:MNE.

\section{Análisis tecnomorfológico de los materiales líticos}

Con anterioridad a la excavación del sitio EQ1, se recolectaron 13 ítems líticos procedentes de superficie y del perfil, mientras que en las seis cuadrículas excavadas se recuperó en planta un total de 764 especímenes. Asimismo, se procesó el material de cernidor de las cuadrículas 1 y 6, contabilizándose un total de 2247 desechos de talla, predominantemente de tamaños pequeños. En este trabajo se presentan los resultados del análisis tecnomorfológico efectuado sobre la totalidad de materiales de planta, de superficie y del perfil ( $\mathrm{n}=777)$, así como de aquellas lascas enteras y fracturadas con talón $(n=199)$ procedentes de cernidor.

La muestra analizada $(n=976)$ está compuesta por desechos de talla $(70,1 \%)$, artefactos formatizados y lascas con filos naturales con rastros (12,9\%), desechos no clasificables $(12,9 \%)$ y núcleos $(4,1 \%)$. La materia prima predominante en el conjunto es la ortocuarcita $(52,6 \%)$, seguida por la ftanita $(41,5 \%)$ y con porcentajes más bajos se encuentran la dolomía silicificada (3\%), el granito $(2,2 \%)$, el cuarzo $(0,3 \%)$, el esquisto $(0,3 \%)$ y el sílice 

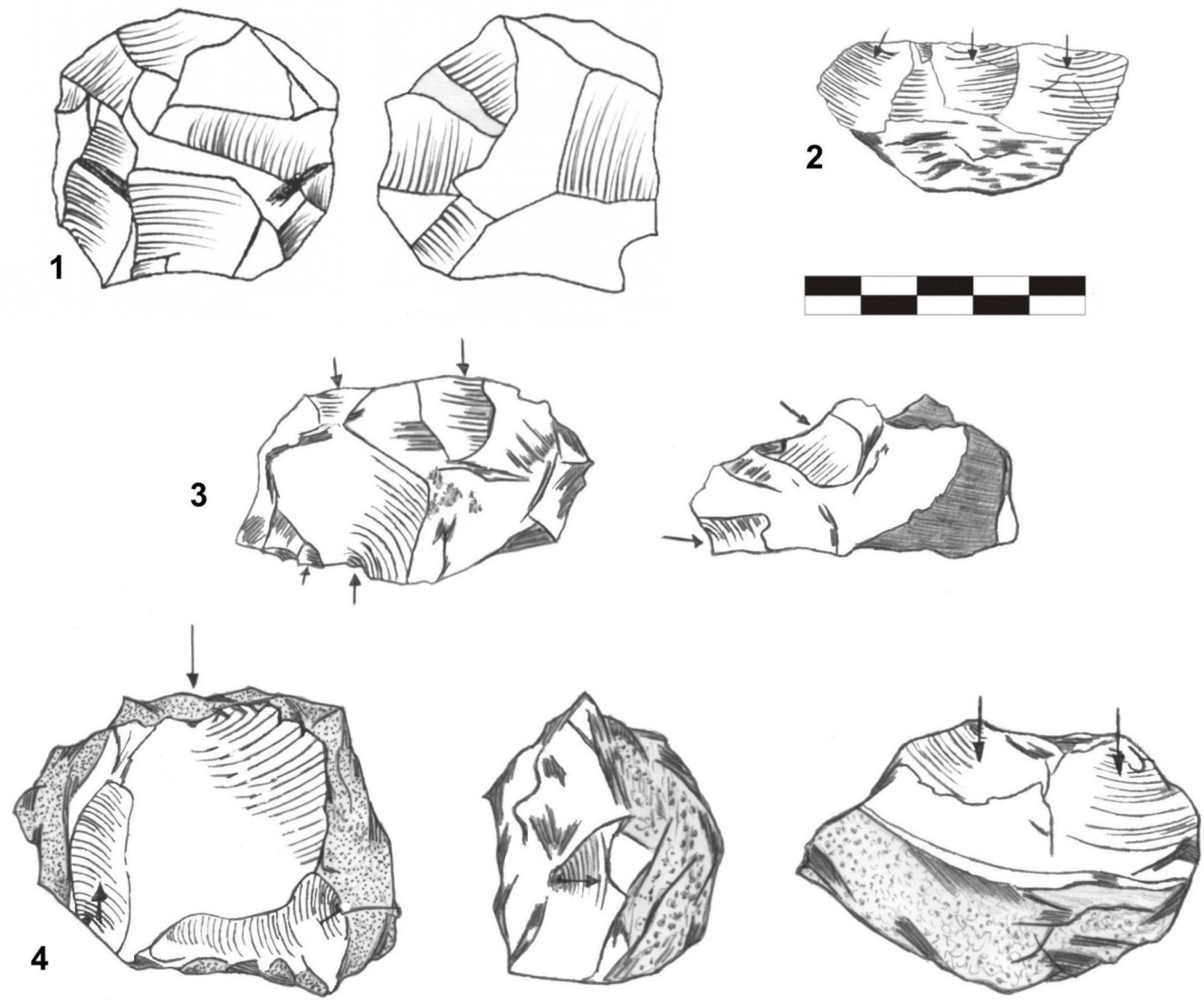

Figura 4. Tipos de núcleos hallados en EQ1. 1) Núcleo poliédrico de ortocuarcita; 2) Núcleo piramidal irregular de ortocuarcita; 3) Núcleo globuloso de ftanita; 4) Núcleo poliédrico de dolomía silicificada.

$(0,1 \%)$. Una de las diferencias observadas entre las materias primas más abundantes es la alta proporción de artefactos formatizados de ortocuarcita (roca no local) y de núcleos de ftanita (roca local).

De los 40 núcleos hallados, 20 están enteros y 20 son fragmentos. Para la descripción de las variables sólo se tuvieron en cuenta los enteros; de estos el $65 \%$ corresponde a ftanita, el $25 \%$ a ortocuarcita y el $10 \%$ restante a dolomía silicificada. Las formas base a partir de las cuales se realizaron los núcleos son en su mayoría indeterminables (ca.70\% del total), lo cual puede deberse al alto grado de reducción y explotación de los mismos. Entre las formas base determinables, los núcleos de ftanita proceden de nódulos (ca.30\%) y sólo uno de una lasca, mientras que los de ortocuarcita fueron realizados sobre lascas grandes $(22 \%)$ y sobre una lasca tabular (7\%). Por su parte, uno de los núcleos de dolomía silicificada proviene de un nódulo (Colantonio 2013). En los tipos de núcleos de ftanita predominan los no diferenciados y los prismáticos irregulares ( $30 \%$ cada uno), seguidos por los piramidales irregulares ( $15 \%)$ y en valores muy bajos el globuloso, discoidal irregular y poliédrico ( $8 \%$ cada uno). En ortocuarcita el tipo más representado es el piramidal irregular (40\%) y en valores inferiores 


\begin{tabular}{|c|c|c|c|c|c|c|c|c|c|c|}
\hline \multirow{2}{*}{ Grupos tipológicos } & \multicolumn{2}{|c|}{ Ortocuarcita } & \multicolumn{2}{|c|}{ Ftanita } & \multicolumn{2}{c|}{ Granito } & \multicolumn{2}{c|}{ Dolomía } & \multicolumn{2}{c|}{ Total } \\
\cline { 2 - 12 } & $\mathbf{n}$ & $\mathbf{0}$ & $\mathbf{n}$ & $\mathbf{0}$ & $\mathbf{n}$ & $\mathbf{\%}$ & $\mathbf{n}$ & $\%$ & $\mathbf{N}$ & $\%$ \\
\hline Artefactos de molienda & 2 & 2,7 & - & - & - & - & - & - & 2 & 1,5 \\
\hline Bifaces & - & - & 3 & 7,5 & - & - & 1 & 25 & 4 & 3,2 \\
\hline Bolas de boleadora & - & - & - & - & 4 & 50 & - & - & 4 & 3,2 \\
\hline Cuchillos & 7 & 9,5 & 5 & 12,5 & - & - & - & - & 12 & 9,5 \\
\hline Filos unifaciales & 5 & 6,7 & 4 & 10 & - & - & 1 & 25 & 10 & 7,9 \\
\hline Fragmentos indeterminados & 11 & 15 & - & - & - & - & - & - & 11 & 8,7 \\
\hline Muescas & 3 & 4 & - & - & - & - & - & - & 3 & 2,3 \\
\hline Percutores & 3 & 4 & - & - & 3 & 37,5 & - & - & 6 & 4,8 \\
\hline Piéce esquillée & - & - & - & - & - & - & 1 & 25 & 1 & 0,7 \\
\hline Artefactos de retoque sumario & 7 & 9,5 & 6 & 15 & - & - & - & - & 13 & 10,3 \\
\hline Preforma de punta de proyectil & - & - & 1 & 2,5 & - & - & - & - & 1 & 0,7 \\
\hline Punta de proyectil apedunculada & - & - & 1 & 2,5 & - & - & & - & 1 & 0,7 \\
\hline Raclettes & 2 & 2,7 & 2 & 5 & - & - & - & - & 4 & 3,2 \\
\hline Raederas & 10 & 13,5 & 3 & 7,5 & - & - & - & - & 13 & 10,3 \\
\hline Raspadores & 6 & 8,2 & 4 & 10 & - & - & 1 & 25 & 11 & 8,7 \\
\hline Cepillos & 1 & 1,3 & - & - & - & - & - & - & 1 & 0,7 \\
\hline Yunques & 1 & 1,3 & - & - & 1 & 12,5 & - & - & 2 & 1,5 \\
\hline Artefactos compuestos & 12 & 16,2 & 4 & 10 & - & - & - & - & 16 & 12,6 \\
\hline Filos naturales con rastros comp. & 4 & 5,4 & 7 & 17,5 & - & - & - & - & 11 & 8,7 \\
\hline Total & 74 & 100 & 40 & 100 & 8 & 100 & 4 & 100 & 126 & 100 \\
\hline
\end{tabular}

Tabla 5. Grupos tipológicos por materia prima del sitio EQ1.

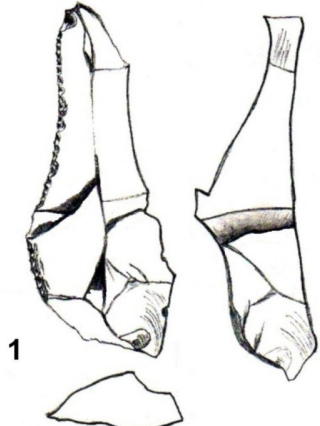

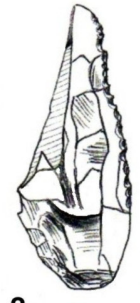

2

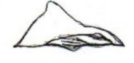

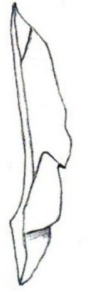

3

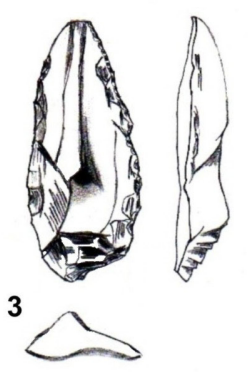

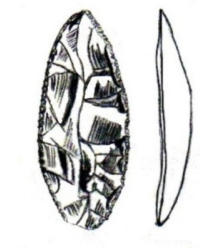

4
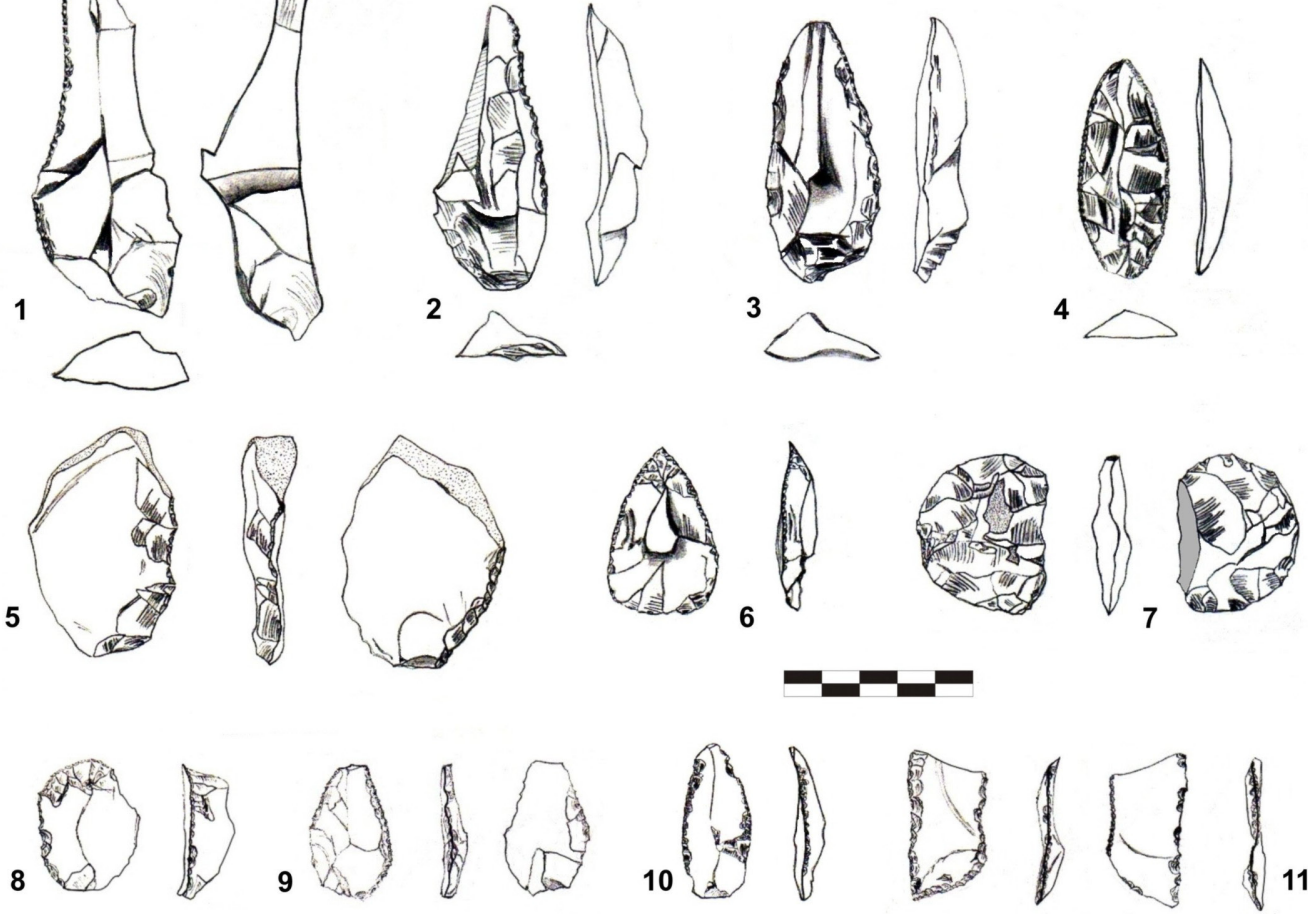

Figura 5. Artefactos formatizados del sitio EQ1. 1-2-3-4) Raederas de ortocuarcita; 5-6) Artefactos compuestos de ortocuarcita; 7) Bifaz de ftanita; 8) Raspador de ftanita; 9-10) Cuchillos de ftanita; 11) Artefacto compuesto de ftanita. 


\begin{tabular}{|c|c|c|c|c|c|c|c|c|}
\hline \multirow{2}{*}{ Tipo de lasca } & \multicolumn{2}{|c|}{ Ortocuarcita } & \multicolumn{2}{|c|}{ Ftanita } & \multicolumn{2}{|c|}{ Dolomía } & \multicolumn{2}{|c|}{ Total } \\
\hline & $\mathbf{n}$ & $\%$ & $\mathbf{n}$ & $\%$ & $\mathbf{n}$ & $\%$ & $\mathbf{N}$ & $\%$ \\
\hline Primaria & - & - & 2 & 1,1 & - & - & 2 & 0,5 \\
\hline Secundaria & 9 & 4,1 & 21 & 11,4 & - & - & 30 & 7 \\
\hline Dorso natural & - & - & 12 & 6,4 & 3 & 19 & 15 & 3,5 \\
\hline Angular & 82 & 37,1 & 64 & 34,6 & 6 & 38 & 152 & 36 \\
\hline Arista & 30 & 13,6 & 17 & 9,2 & 1 & 6 & 48 & 11,4 \\
\hline Plana & 13 & 5,9 & 3 & 1,6 & - & - & 16 & 3,8 \\
\hline Cresta & - & - & 2 & 1,1 & - & - & 2 & 0,5 \\
\hline Bipolar & - & - & - & - & 1 & 6 & 1 & 0,25 \\
\hline Adelgazamiento & 12 & 5,4 & 6 & 3,2 & - & - & 18 & 4,3 \\
\hline Reducción & 18 & 8,1 & 27 & 14,6 & 1 & 6 & 46 & 11 \\
\hline Reactivación & 19 & 8,6 & 8 & 4,3 & 3 & 19 & 30 & 7 \\
\hline Tableta de núcleo & - & - & 1 & 0,6 & - & - & 1 & 0,25 \\
\hline Indiferenciada & 38 & 17,2 & 22 & 11,9 & 1 & 6 & 61 & 14,5 \\
\hline Total & 221 & 100 & 185 & 100 & 16 & 100 & 422 & 100 \\
\hline \multicolumn{9}{|l|}{ Tipo de talón } \\
\hline Cortical & 12 & 4,1 & 20 & 8,3 & 4 & 22,2 & 36 & 6,6 \\
\hline Liso & 200 & 69 & 148 & 61,4 & 9 & 50 & 357 & 65 \\
\hline Diedro & 14 & 4,8 & 16 & 6,6 & 1 & 5,6 & 31 & 5,6 \\
\hline Facetado & 4 & 1,4 & 13 & 5,5 & 1 & 5,6 & 18 & 3,3 \\
\hline Filiforme & 40 & 13,8 & 24 & 9,9 & - & - & 64 & 11,6 \\
\hline Puntiforme & 2 & 0,7 & 5 & 2 & 1 & 5,6 & 8 & 1,5 \\
\hline Fracturado & 16 & 5,5 & 13 & 5,5 & - & - & 29 & 5,3 \\
\hline Indiferenciado & 2 & 0,7 & 2 & 0,8 & 2 & 5,6 & 6 & 1,1 \\
\hline Total & 290 & 100 & 241 & 100 & 18 & 100 & 549 & 100 \\
\hline
\end{tabular}

Tabla 6. Tipos de lascas y talones para los desechos de talla de EQ1 (para las lascas sólo fue considerada la categoría enteras).

se encuentran el poliédrico, prismático y de lascados aislados (20\% cada uno). En dolomía silicificada se reconoció un núcleo poliédrico y uno indiferenciado (Figura 4).

Con relación a la dirección de los lascados, los núcleos de ortocuarcita presentan un $60 \%$ de extracciones unidireccionales y un $40 \%$ de bidireccionales. En ftanita las extracciones multidireccionales son las más frecuentes (54\%), seguidas por las bidireccionales $(30 \%)$ y las unidireccionales $(16 \%)$. Por su parte, los dos núcleos de dolomía silicificada poseen lascados multidireccionales (Colantonio 2013). Los núcleos de ftanita presentan tamaños mediano-grande (70\%) y corteza en diferentes frecuencias (75\%). La misma situación se registra para la dolomía silicificada en la cual ambos núcleos presentan corteza y son de tamaño mediano-grande y grande. Por su parte, en los núcleos de ortocuarcita predominan los tamaños grandes $(60 \%)$ y poseen corteza en frecuencias menores que los de ftanita (la mitad tiene menos del $40 \%$ de corteza y el $28,5 \%$ no presenta).

Con respeto a los artefactos formatizados, se registró una alta variabilidad de grupos tipológicos, así como la presencia de una elevada frecuencia de lascas con filos naturales con rastros (Tabla 5; Figura 5). Los primeros corresponden a artefactos compuestos (12,6\%), piezas de retoque sumario y raederas $(10,3 \%$ cada uno), cuchillos $(9,5 \%)$, raspadores y fragmentos de artefactos formatizados ( $8,7 \%$ cada uno), filos unifaciales $(7,9 \%)$ y otros grupos 


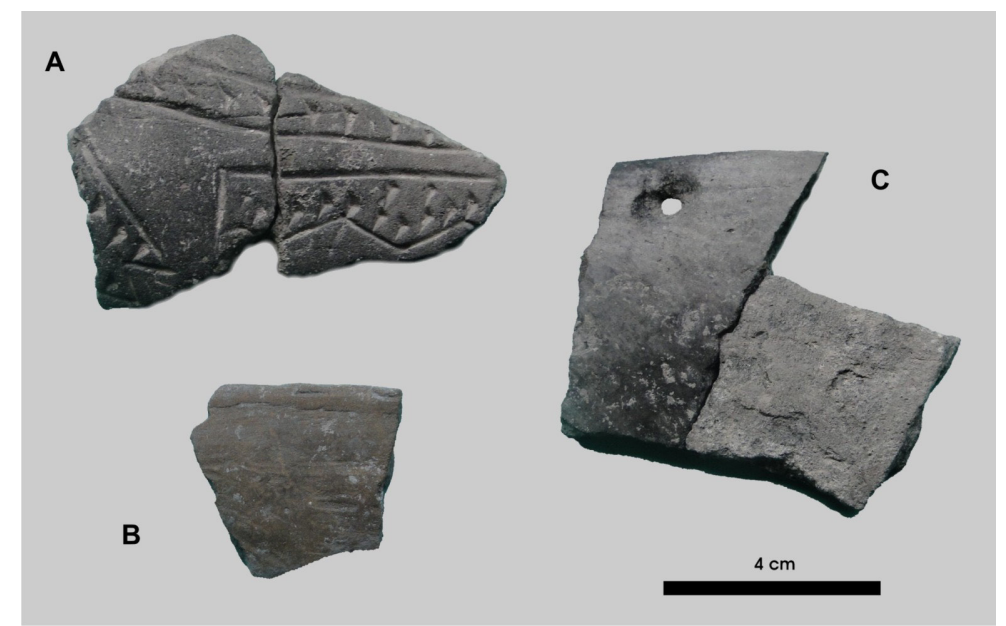

Figura 6. Fragmentos cerámicos hallados en el sitio EQ1. A) Fragmentos remontados de cuerpo con decoración incisa; B) Fragmento de borde; C) Fragmentos remontados de borde y cuerpo con agujero.

en bajas frecuencias (e.g., bifaces, artefactos de molienda, percutores, boleadoras, muescas, entre otros). Además, se determinó una preforma y una punta de proyectil triangular apedunculada pequeña. De los 16 artefactos compuestos, la mayoría fueron confeccionados sobre ortocuarcita (75\%), mientras que los de ftanita sólo alcanzan el 25\%.

En los artefactos formatizados por talla enteros de ortocuarcita predominan los tamaños mediano-grandes y grandes (34\% y 32\%, respectivamente); mientras que los de ftanita son en su mayoría de tamaño mediano-grande y mediano pequeño (54\% y 34\%, respectivamente). Sólo en ortocuarcita se hallan representados los tamaños muy grandes $(10 \%)$. En cuanto a las formas base seleccionadas, se observa que en ortocuarcita y ftanita corresponden en su mayoría a lascas (85,5\% y 90\%, respectivamente). Según Colantonio (2013), los artefactos formatizados de ortocuarcita fueron confeccionados sobre soportes con tendencia laminar, mientras que en los de ftanita predominan los soportes más cortos (Figura 5).

En cuanto a los desechos de talla $(n=684)$, se registró un $63 \%$ de lascas enteras, un $19 \%$ de fracturadas con talón y un $18 \%$ de fracturadas sin talón (la alta frecuencia de los dos primeros grupos se debe a que de la muestra de cernidor sólo se analizaron estos estados). Dentro de los desechos de talla, el 52,6\% son de ortocuarcita, el 43\% de ftanita, el 2,9\% de dolomía silicificada y en porcentajes menores al 1\% se registró granito, cuarzo, sílice y una materia prima indeterminable. Entre las lascas enteras, las internas son las más frecuentes para las tres materias primas mejor representadas, predominando las lascas angulares (entre ca. 38\% y 34\%) y los talones lisos (entre ca. 69\% y 50\%), aunque se han registrado algunas diferencias vinculadas con las trayectorias de explotación de las distintas rocas (Tabla 6). En ortocuarcita se destaca una frecuencia moderada para las lascas indeterminables (17\%), de arista $(13,6 \%)$ y de reactivación $(8,6 \%)$, estando las lascas externas presentes en muy bajas frecuencias $(4 \%)$. Por su parte, en ftanita se reconoce un porcentaje intermedio para las lascas externas $(18,9 \%)$ y de reducción $(14,6 \%)$, en tanto que para la dolomía silicificada se destacan las de reactivación y de dorso natural (ca.19\%). Los restantes tipos de lascas y talones se registran con frecuencias muy bajas (Tabla 6). 


\section{Análisis de la cerámica}

Los tiestos estudiados corresponden a todos aquellos provenientes de plantas de excavación, así como los recuperados en la separación de los materiales de cernidor de tres cuadrículas (1, 2 y 6), lo cual hace un total de 57 fragmentos. El estudio de su distribución indicó la presencia de dos picos de densidades mayores, uno de ellos en la sección superior del horizonte A del suelo enterrado 2Ab1 (entre 60 y $90 \mathrm{~cm}$ ) con el 49,1\% y el otro en el horizonte $2 \mathrm{Cb} 1$ (entre 105 y $140 \mathrm{~cm}$ ) con el 43,9\%. Un fragmento asociado al suelo enterrado $2 \mathrm{Ab} 2$ hallado a una profundidad de $145-150 \mathrm{~cm}$ (encontrado en una grieta) remontó con uno proveniente del nivel $130-135 \mathrm{~cm}$, por lo cual se plantea que dicho tiesto no estaría vinculado con el fechado de 3100 años AP. Por su parte, un tiesto fue recuperado por debajo del lente de gastrópodos (misma cuadrícula y sector) y por encima del suelo enterrado $2 \mathrm{Ab} 2$, indicando una posible asociación con la cronología de 2800 años AP. Sin embargo, dada la presencia de grietas en la estratigrafía del sitio y la posible migración de materiales, no puede corroborarse la cronología estimada hasta tanto se efectúe una datación directa sobre el fragmento cerámico.

La totalidad de los tiestos recuperados está representada por 8 bordes, uno de los cuales presentaba un agujero de suspensión o reparación, y 49 fragmentos de cuerpo (Figura 6). El 26,3\% de los tiestos está decorado, tanto fragmentos de bordes $(n=2)$ como de cuerpo $(\mathrm{n}=13)$. Entre los tiestos decorados, 10 presentan incisiones y/o impresiones sobre la superficie externa y cinco poseen pintura roja sobre la superficie interna. Entre los motivos geométricos incisos se destacan líneas rectas y en zigzag, líneas rectas dobles e impresiones rítmicas. Las tareas de remontaje permitieron ensamblar un total de 13 fragmentos; cinco conformados por dos tiestos y el restante por tres. En escasos tiestos se pudo identificar que la técnica constructiva fue la de superponer rodetes de arcilla. Hasta el momento se estimó un número mínimo de contenedores de siete, para lo cual se contabilizaron los bordes con y sin representaciones $(n=5)$ y los fragmentos de cuerpo con algún tipo de motivo $(n=1)$ o con un tratamiento particular de la superficie $(n=1)$. Posiblemente el número de contenedores aumente cuando se efectúen estudios detallados de las características macroscópicas de los tiestos y microscópicas de las pastas.

\section{Discusión de las distintas líneas de evidencia}

La información estratigráfica indica que el contexto arqueológico se encuentra incluido en depósitos de origen fluvial referibles al Miembro Río Salado de la Formación Luján, secuencia en la que se ha registrado el desarrollo de tres suelos (Figura 1c). Las especies de gastrópodos identificadas en el suelo enterrado $2 \mathrm{Ab} 2$ sugieren la existencia de un ambiente palustre. Además, durante el desarrollo de la unidad 2Ab1 se registra en otros sectores del sitio un rasgo lenticular formado por gastrópodos fluviales y lacustres, restos de peces y plantas acuáticas. Por su parte, en la parte media y superior del perfil se observaron uno o más eventos de inundación marcadamente erosivos que han generado discordancias con contactos irregulares entre las unidades, incluso rellenando cuevas, que evidencian a su vez la acción de animales fosoriales. Los diversos estudios geoambientales sugieren que el perfil del sitio corresponde a la planicie de inundación del arroyo Tapalqué.

La asociación entre los armadillos en el sitio es similar a lo largo de toda la secuencia y es significativo que Dasypus hybridus se halla presente en todos los niveles excavados. Esta especie de estirpe brasílica se reconoce hacia el centro de la provincia de Buenos Aires 
recién en el Holoceno tardío inicial, mientras que en las sierras australes se registra hacia el Holoceno tardío final (Vizcaíno et al. 1995). Según Abba y Vizcaíno (2011) la asociación de Chaetophractus villosus y Dasypus hybridus está vinculada con condiciones ambientales similares a las actuales. La presencia de dicha asociación en EQ1 en el Holoceno tardío inicial (entre ca. 3100-2000 años AP) coincide con la propuesta de Prieto et al. (2009) en la cual se plantea, a través de estudios palinológicos efectuados en la zona del Empalme Querandíes, la existencia de condiciones húmedas similares a las actuales para los últimos 3000 años en el centro de la subregión Pampa Húmeda. En el caso de Tolypeutes matacus, actualmente no se encuentra en la región y se ha propuesto que se habría retraído del sudeste pampeano durante el Holoceno medio debido a que esta especie se adapta a condiciones tropicales a subtropicales con estación seca (Vizcaíno et al. 1995). En lo que respecta a su presencia en el sitio, podría ser explicada como un relicto de una fase árida o por la proximidad de EQ1 al cordón serrano de Tandilia (ver Abba y Vizcaíno 2011). Sin embargo, estas inferencias deben ser consideradas con cautela, dado que el conjunto presenta perturbaciones postdepositacionales.

Con relación a la información tafonómica y a los procesos de formación, se determinó que el sitio EQ1 presenta una baja integridad y resolución. Entre los agentes que han intervenido en su formación se destaca la mezcla de materiales producida por cuevas de animales de hábitos fosoriales (probablemente armadillos) y la presencia de grietas en el sedimento, en las cuales parte del material estaba incluido, presentado una horizontalidad mala (i.e., posición vertical). Es como producto de la baja resolución e integridad que se consideró que no era posible, con la evidencia actualmente disponible, separar eventos de ocupación o conjuntos de niveles en este sitio multicomponente, que dieran cuenta de los distintos momentos de ocupación llevados a cabo durante el Holoceno tardío inicial (entre ca. 3100 y 2000 años AP).

Por su parte, los resultados del análisis tafonómico indican que los perfiles de partes esqueletarias de Lama guanicoe no habrían sido afectados por procesos mediados por la densidad mineral de los restos óseos (Álvarez 2012), como por ejemplo, el transporte fluvial y/o las características palustres a lo largo de la secuencia estratigráfica. Sobre la base de esto, es probable que la abrasión sedimentaria se haya desarrollado in situ. Considerando esta posibilidad, se realizó una correlación de Rho de Spearman entre los perfiles de abrasión y meteorización. La misma resultó significativa y negativa $(\mathrm{p}=0,0001 ; \mathrm{Rs}=-0,126)$, indicando que probablemente el agua haya protegido a los huesos de la meteorización. La misma situación podría plantearse para los escasos porcentajes de marcas de roedores y carnívoros (Tabla 4), dado que el contexto de anegamiento en el sitio podría haber generado que los restos no estuvieran disponibles para estos agentes. Por otro lado, es probable que en eventos puntuales de inundación el agua haya actuado con mayor energía, incluso provocando el transporte de unidades esqueletarias articuladas. Teniendo en cuenta los aspectos mencionados, la presencia de las dos concentraciones óseas con restos articulados alerta acerca de la posibilidad de que por lo menos parte de los elementos hayan ingresado al mismo por causas naturales. Sin embargo, esto no implica necesariamente que su origen no sea antrópico. Los análisis efectuados hasta el momento por Álvarez (2012) no han permitido aún dilucidar el origen de estas acumulaciones, el cual podrá ser determinado con mayor precisión una vez que finalicen las excavaciones.

Respecto del aprovechamiento antrópico, se destaca el procesamiento de diversos animales tales como Lama guanicoe, Ozotoceros bezoarticus, Lagostomus maximus, Myocastor coypus, Rhea americana y las cuatro especies de armadillos (placas con alteración térmica). El 
mayor porcentaje de huellas en Lama guanicoe se encuentra en el esqueleto axial, particularmente en las costillas y vértebras, aunque también en algunos huesos largos; mientras que en Ozotoceros bezoarticus fueron identificadas tanto en el esqueleto axial como en el apendicular. El análisis de los perfiles de partes esqueletarias de Lama guanicoe indica el transporte de unidades de alto contenido de carne y médula, aunque la correlación con el Índice de Carne fue positiva pero no significativa $(p=0,509$ y Rs=0,129). En el caso de Ozotoceros bezoarticus y Rhea americana, también están representados especímenes con alto contenido de médula y carne. A su vez, si bien los materiales dentarios fueron escasos, las determinaciones realizadas permiten proponer que el sitio fue ocupado en distintos momentos a lo largo de todo el año.

Por último, se destacan algunos aspectos tecnológicos vinculados a la utilización de los restos óseos como materia prima, como es el caso de la tibia de Lama guanicoe, del hueso largo que posiblemente corresponda a Rhea americana y de la cornamenta de Ozotoceros bezoarticus. Este último caso constituye un registro novedoso, ya que el cráneo presentaba las astas quemadas y fracturadas a la altura de las rosetas. Según los estudios efectuados por Álvarez (2012) la alteración térmica fue producida antes de realizar la fractura intencional de las astas, posiblemente con el objetivo de eliminar el terciopelo y así obtener una cornamenta endurecida.

Respecto del material lítico, se observaron diferencias en la representación de las rocas recuperadas en el sitio EQ1, lo cual evidencia que fueron utilizadas de distintas maneras. Esto puede comprobarse a través de los objetivos de producción y en las diferentes estrategias tecnológicas utilizadas para cada materia prima. Las cadenas operativas de las rocas locales (i.e., ftanita y dolomía silicificada) son más largas y completas, representando las distintas etapas de la secuencia de reducción lítica, que van desde el descortezamiento de los núcleos (ca. 19\% de lascas externas) hasta la formatización y mantenimiento de los filos en el sitio. En cambio, la cadena operativa de las materias primas no locales (e.g., ortocuarcita) son más cortas, registrándose escasa representación de las primeras actividades de producción lítica (ca. $4 \%$ de lascas externas) y mayor de aquellas vinculadas con la obtención de formas base y con las últimas etapas de formatización de instrumentos y mantenimiento de los mismos (Colantonio 2013).

En las distintas materias primas se infiere un alto grado de explotación y reducción de los núcleos, que se evidencia en la utilización de varias plataformas de percusión y en la multiplicidad de direcciones de las extracciones. Sin embargo, se registran diferencias que pueden estar vinculadas con la forma en que las rocas ingresaron al sitio, con el modo de explotación y con los soportes buscados. La ortocuarcita habría ingresado a EQ1 en forma de núcleos en un estado avanzado de reducción, de lascas gruesas y de instrumentos. El objetivo de extracción en los núcleos fueron lascas con módulos laminares para confeccionar ciertos tipos de instrumentos (raederas y artefactos compuestos), en las cuales se observó el adelgazamiento de los soportes para obtener un espesor determinado. En cambio, la ftanita ingresó como nódulos de tamaño reducido, algunos de los cuales fueron descortezados en el sitio, pero también como núcleos. De estos últimos se realizaron extracciones, en su mayoría de lascas cortas y anchas, sobre las cuales se confeccionaron raspadores, cuchillos y piezas con retoque sumario, entre otros. Asimismo, se reconoce el mantenimiento y el uso de diversos tipos de instrumentos manufacturados por picado, abrasión y pulido confeccionados sobre rocas locales de composición granitoide (Tabla 5). 
Con respecto a la tecnología cerámica, se destaca la alta frecuencia de tiestos con relación a otros sitios de la cuenca superior del Arroyo Tapalqué como Laguna La Barrancosa 1 y 2, Arroyo Tapalqué 1 y Blanca Chica (Messineo 2011), con la excepción del sitio Calera (Di Prado 2013). En los contenedores cerámicos se registraron motivos geométricos realizados por inciso de línea llena (e.g., rectas y en zigzag, líneas rectas dobles) e inciso rítmico (impresiones) y se observó pintura como acabado de la superficie interna. Por otro lado, algunos tiestos presentaban hollín sobre la superficie externa, sugiriendo que parte de los contenedores estuvieron destinados al preparado y cocción de los alimentos. Los resultados obtenidos sobre este tipo de tecnología son preliminares y futuros trabajos estarán destinados a una mejor caracterización de la composición de las pastas y de los tratamientos de la superficie.

En síntesis, el presente enfoque multidisciplinario sugiere que parte de las ocupaciones del sitio EQ1 estarían vinculadas con loci de actividades múltiples de campamentos base. Entre dichas actividades se destaca el procesamiento de diversos animales, la producción y uso de una amplia gama de artefactos líticos manufacturados por talla y por picado, la confección de instrumentos óseos, el uso de pigmentos minerales y la utilización de recipientes cerámicos. Además, es notable la presencia de bienes vinculados con otras áreas de la región pampeana (e.g., caracoles marinos y una cuenta en valva). Un registro novedoso, no sólo para EQ1 sino para el sudeste pampeano, lo constituye la punta de proyectil confeccionada en hueso. Según las características morfológicas y las dimensiones, dicha punta es similar a las encontradas en los sitios Anahí y La Bellaca 2 del noroeste de la provincia de Buenos Aires (Buc y Loponte 2007) y de aquellos especímenes hallados tanto en localidades residenciales (sitio Arroyo Talainín 2) como en contextos mortuorios y sitios de agregación de las sierras de Córdoba (Pastor et al. 2005; Rivero y Recalde 2012). Según Pastor y colaboradores (2005) estas puntas se encuentran asociadas con la tecnología del arco y la flecha. Un tema que requiere mayor investigación es la cronología de este tipo de armas, ya que los sitios mencionados se encuentran ubicados cronológicamente en los últimos 1100 años AP, mientras que las dataciones obtenidas hasta el momento para EQ1 señalan una ocupación del Holoceno tardío inicial, aspecto que deberá ser corroborado con un fechado de la pieza.

\section{Conclusiones}

El sitio EQ1 se caracteriza por una historia tafonómica compleja, en la cual han intervenido distintos agentes que generaron un registro con una muy baja integridad y resolución. Entre estos puede mencionarse la acción hídrica, los animales con hábitos fosoriales y la presencia de grietas en el sedimento como los factores que han tenido mayor incidencia en la mezcla de los materiales. No obstante, si bien el contexto del sitio no permite por el momento identificar la presencia de componentes o afinar la resolución a un grano más fino, el mismo provee valiosa información si se lo considera en la escala adecuada, en este caso, el Holoceno tardío inicial. La evidencia obtenida en EQ1 muestra similitudes con relación al modelo de ocupación humana del Holoceno tardío postulado para la cuenca superior del Arroyo Tapalqué (Messineo 2011), entre las que se destacan una subsistencia basada en el consumo de Lama guanicoe, complementada con otras especies animales como Ozotoceros bezoarticus, Rhea americana y armadillos; una estrategia tecnológica expeditiva sobre las materias primas locales y una mayor estandarización sobre las rocas no locales. Entre las principales diferencias registradas se puede mencionar la predominancia de la ortocuarcita en relación con otras materias primas locales y la alta frecuencia de cerámi- 
ca en el contexto del sitio. La funcionalidad atribuida a EQ1 es concordante con la mayor frecuencia de loci de actividades múltiples para este lapso temporal. Por último, la presencia de caracoles marinos y la punta de proyectil en hueso (vinculada posiblemente a contextos de otras áreas/regiones) estaría señalando la existencia de circuitos de intercambio intra y extra-pampeanos, aspecto que ya ha sido reconocido para otros sitios arqueológicos del centro de la subregión Pampa Húmeda.

\section{Agradecimientos}

A las personas que colaboraron en las tareas de excavación y laboratorio. Las investigaciones en el sitio fueron financiadas por la ANPCYT a través del subsidio PICT 08-0430 otorgado a un de los autores (PGM). Este artículo es una producción de la Unidad Ejecutora INCUAPA-CONICET (Investigaciones Arqueológicas y Paleontológicas del Cuaternario Pampeano) dirigido por el Dr. Gustavo Politis y el Lic. José Luis Prado. Las opiniones vertidas en el presente trabajo son de nuestra absoluta responsabilidad.

\section{Bibliografía citada}

Abba, A. M. y S. F. Vizcaíno

2011 Distribución de los armadillos (Xenarthra: Dasypodidae) en la provincia de Buenos Aires, Argentina. Mastozoología Neotropical 18 (2): 185-206.

Álvarez, M. C.

2012 Análisis zooarqueológicos en el Sudeste de la región pampeana. Patrones de subsistencia durante el Holoceno tardío. Tesis Doctoral inédita. Facultad de Ciencias Sociales, Universidad Nacional del Centro de la Provincia de Buenos Aires. Olavarría.

Aschero, C. A.

1975 Ensayo para una clasificación morfológica de artefactos líticos. Informe presentado al CONICET. 1983 Registro de códigos para atributos descriptivos aplicados a artefactos líticos. Informe presentado al CONICET.

Aschero, C. A. y S. Hocsman

2004 Revisando cuestiones tipológicas en torno a la clasificación de artefactos bifaciales. Registros del Pasado 1 (ed. por M. Ramos, A. Acosta y D. Loponte), pp. 2-25. Univ. Nacional de Luján, Luján.

Behrensmeyer, A. K.

1978 Taphonomic and ecologic information from bone weathering. Paleobiology 4 (2): 150-162.

Bellelli, C., A. Guráieb y J. García

1985-1987 Propuesta para el análisis y procesamiento por computadora de desechos de talla lítica (DELCO - Desechos líticos computarizados). Arqueología Contemporánea 2 (1): 36-53.

Bennett, J. L.

1999 Thermal alteration of buried bone. Journal of Archaeological Science 26: 1-8.

Binford, L.

1978 Nunamiut Etnoarchaeology. Academic Press, New York.

1981 Bones: Ancient Men and Modern Myths. Academic Press, New York. 
Buc, N. y D. Loponte

2007 Bone tool types and microwear patterns: some examples from the Pampa region, South America. Bones as Tools: Current Methods and Interpretations in Worked Bone Studies (ed. por C. Gates St-Pierre y R. B. Walker), pp. 143-157. BAR International Series 1622. Oxbow, Oxford.

Butzer, K. W.

1982 Archaeology as Human Ecology: Method and Theory for a Contextual Approach. Cambridge University Press, Cambridge.

Cabrera, A. L.

1968 Vegetación de la provincia de Buenos Aires. Flora de la Provincia de Buenos Aires (ed. por A. L. Cabrera), Parte 1, pp. 101-123. Colección Científica del INTA, Buenos Aires.

Cabrera, A. L. y A. W. Willink

1980 Biogeografía de América Latina. Serie de Biología. Monografía Nro. 13. Secretaría General de la Organización de los Estados Americanos. Programa Regional de Desarrollo Científico y Tecnológico. Washington D.C.

Colantonio, M. J.

2013 Análisis de la tecnología lítica de cazadores-recolectores del centro de la subregión Pampa Húmeda durante el Holoceno tardío (provincia de Buenos Aires). Tesis de Licenciatura inédita. Facultad de Ciencias Sociales, Universidad Nacional del Centro de la Provincia de Buenos Aires. Olavarría.

David, B.

1990 How was this bone burnt? Problem Solving in Taphonomy: Archaeological and Palaeontological Studies from Europe, Africa and Oceania (ed. por S. Solomon, I. Davidson y D. Watson), Tempus Vol. 2, pp. 65-79. University of Queensland, Queensland.

Di Prado, V.

2013 Estudio de la alfarería del sitio Calera (partido de Olavarría, provincia de Buenos Aires, Argentina) desde la perspectiva del estilo tecnológico. Revista del Museo La Plata, Arqueología 13.

Fidalgo, F., R. O. Gentile y H. A. Correa 1986 Geología y geomorfología en la cuenca del Arroyo Tapalqué. Informe 30. Presentado a la Comisión de Investigaciones Científicas de la Provincia de Buenos Aires, La Plata.

Fidalgo, F., J. C. Riggi, R. O. Gentile, H. A. Correa y N. Porro

1991 Los "Sedimentos Postpampeanos" continentales en el ámbito sur bonaerense. Revista de la Asociación Geológica Argentina 46 (3-4): 239-256.

Franco, N. V.

1991 Algunas tendencias distribucionales en el material lítico recuperado en el área Interserrana Bonaerense. Boletín del Centro 3: 72-79.

1994 Maximización en el aprovechamiento de los recursos líticos. Un caso analizado en el Área Interserrana Bonaerense. Arqueología de Cazadores-Recolectores. Limites, Casos y Aperturas (comp. por L. A. Borrero y J. L. Lanata). Arqueología Contemporánea 5: 75-88. 
Grayson, D. K.

1984 Quantitative Zooarchaeology: Topics in the Analysis of Archaeological Faunas. Academic Press, Orlando.

Gutiérrez, M. y C. Kaufmann

2007 Methodological criteria for the identification of formation processes in guanaco (Lama guanicoe) bone assemblages in fluvial-lacustrine environments. Journal of Taphonomy 5 (4): 151-176.

Haynes, G.

1980 Evidence of carnivore gnawing on Pleistocene and recent mammalian bones. Paleobio$\log y$ 6: 341-351.

Holliday, V. T., C. Reid Ferring y P. Goldberg

1993 The scale of soil investigations in archaeology. Effects of Scale on Archaeological and Geoscientific Perspectives (ed. por J. K. Stein y A. R. Linse), pp. 29-37. Geological Society of America, Special Paper 238.

Johnson, E.

1985 Current developments in bone technology. Advances in Archaeological Method and Theory 8:157-235.

Kaufmann, C. A.

2009 Metodologías para la Construcción de Perfiles de Mortalidad y Determinación de la Estacionalidad en Restos Oseos de Guanacos (Lama guanicoe). Su Aplicación a Sitios Arqueológicos de la Región Pampeana. Sociedad Argentina de Antropología, Buenos Aires.

Klein, R. y K. Cruz-Uribe

1984 The Analysis of Animal Bones from Archaeological Sites. Chicago University Press, Chicago.

Kotzian, C. B. y M. G. Simões

2006 Taphonomy of recent freshwater molluscan death assemblages, Touro Passo Stream, southern Brazil. Revista Brasileira de Paleontologia 9 (2): 243-260.

Laprida, C., M. J. Orgeira y N. García Chapori

2009 El registro de la pequeña edad de hielo en lagunas pampeanas. Revista de la Asociación Geológica Argentina 65 (4): 603-611.

Lyman, R. L.

1994 Vertebrate Taphonomy. Cambridge Manuals in Archaeology, Cambride University Press, Cambridge.

2008 Quantitative Paleozoology. Cambridge Manuals in Archaeology, Cambridge University Press, Cambridge.

McCormac, F. C., A. G. Hogg, P. G. Blackwell, C. E. Buck, T. F. G. Higham y P. J. Reimer 2004 SHCal04 Southern Hemisphere Calibration 0-11.0 cal kyr BP. Radiocarbon 46: 1087-1092.

Messineo, P. G.

2011 Investigaciones arqueológicas en la cuenca superior del Arroyo Tapalqué. Un modelo de ocupación humana para el centro de la subregión Pampa Húmeda durante el Holoceno tardío. Intersecciones en Antropología 12: 275-291. 
Messineo, P. G., M. C. Álvarez, C. Favier Dubois, P. Steffan y M. J. Colantonio

2011 Primeros resultados de las investigaciones arqueológicas en el sitio Empalme Querandíes 1 (Olavarría, Buenos Aires). Revista del Museo de la Plata, Arqueología 12 (86): 57R. La Plata.

Olsen, S. L. y P. Shipman

1988 Surface modification on bone: trampling versus butchery. Journal of Archaeological Science 15: 535-553.

Orgeira, M. J., A. M. Walther, R. O. Tófalo, C. A. Vásquez, H. Lippai y R. Compagnucci 2001 Estratigrafía y magnetismo de rocas en un perfil cuaternario. Implicancias paleoambientales y paleoclimáticas. Ao. Tapalqué, Provincia de Buenos Aires. Revista de la Asociación Geológica Argentina 56 (3): 353-366.

Orton, C., P. Tyers y A. Vince

1997 La Cerámica en Arqueología. Crítica, Barcelona.

Pastor, S., E. Pautassi y D. Rivero

2005 Los sistemas de armas de las comunidades agroalfareras de Córdoba: una aproximación arqueológica y experimental. Actas del XIII Congreso Nacional de Arqueología Argentina, Tomo IV, pp. 253-265. Córdoba.

Poiré, D. G., y L. A. Spalletti

2005 La cubierta sedimentaria Precámbrica-Paleozoica inferior del Sistema de Tandilia. Relatorio XVI Congreso Geológico Argentino. Geología y Recursos Minerales de la Provincia de Buenos Aires (ed. por R. R. de Barrio, R. O. Etcheverry, M. F. Caballé, E. Llambías), pp. 51-68. La Plata.

Prieto, A. R., I. Vilanova, M. S. Tonello y S. Stutz

2009 Reconstrucción de la vegetación y del clima de los pastizales pampeanos durante el Pleistoceno tardío-Holoceno a través del análisis palinológico. Quaternário do Rio Grande do Sul: Integrando Conhecimentos, pp. 107-120. Monografias da Sociedade Brasileira de Paleontologia, Porto Alegre.

Rice, P. M.

1987 Pottery Analysis. A Sourcebook. The University of Chicago Press, Chicago.

Ringuelet, R. A.

1961 Rasgos fundamentales de la zoogeografía de la Argentina. Phycis 22 (63): 151-170.

Rivero, D. y M. A. Recalde

2012 El uso del arco en la guerra durante el prehispánico tardío de las Sierras de Córdoba. Armas Prehispánicas: Múltiples Enfoques para su Estudio en Sudamérica (comp. por J. G. Martínez y D. L. Bozzuto), pp. 151-171. Fundación de Historia Natural Félix de Azara, Buenos Aires.

Scheifler, N., P. Teta y U. F. J. Pardiñas

2012 Small mammals (Didelphimorphia and Rodentia) of the archaeological site Calera (Pampean region, Buenos Aires Province, Argentina): Taphonomic history and Late Holocene environments. Quaternary International 278: 32-44. 
Shipman, P.

1981a Life History of a Fossil. Cambridge. Harvard University Press.

1981b Applications of scanning electron microscopy to taphonomic problems. The Research Potential of Anthropological Museum Collections (ed. por A. M. Cantwell, J.B. Griffin y N. Rotschild). Annals of the New York Academy of Science 376: 357-385.

Steffan, P. G.

2009 Reconstrucción paleoambiental de contextos arqueológicos del Área Interserrana. Tesis Doctoral inédita. Facultad de Ciencias Naturales y Museo, Universidad Nacional de La Plata. La Plata.

Vizcaíno, S. F., U. F. J. Pardiñas y M. S. Bargo

1995 Distribución de los armadillos (Mammalia, Dasypodidae) en la región Pampeana (Republica Argentina) durante el Holoceno. Interpretación paleoambiental. Mastozoología Neotropical 2: 149-165.

Wolverton, S.

2002 NISP:MNE and \% whole in analysis of prehistoric carcass exploitation. North American Archaeologist 23 (2): 58-100. 